AUTARQUIA ASSOCIADA À UNIVERSIDADE DE SÃO PAULO

\title{
DETERMINAÇÃO DOS RADIONUCLÍDEOS NATURAIS URÂNIO E TÓRIO NOS SEDIMENTOS SUPERFICIAIS DO SISTEMA CANANÉIA-IGUAPE
}

Luiz Flávio Lopes Teixeira

\begin{abstract}
Dissertação apresentada como parte dos requisitos para obtenção do Grau de Mestre em Ciências na Área de Tecnologia Nuclear - Aplicações
\end{abstract}

Orientadora:

Profa. Dra. Barbara Paci Mazzilli 
INSTITUTO DE PESQUISAS ENERGÉTICAS E NUCLEARES

Autarquia associada à Universidade de São Paulo

DETERMINAÇÃO DOS RADIONUCLÍDEOS NATURAIS URÂNIO E TÓRIO NOS SEDIMENTOS SUPERFICIAIS DO SISTEMA CANANÉIA-IGUAPE

Luiz Flávio Lopes Teixeira

Dissertação apresentada como parte dos requisitos para obtenção do Grau de

Mestre em Ciências na Área

de Tecnologia Nuclear - Aplicações

Orientadora:

Profa. Dra. Barbara Paci Mazzilli

Versão Corrigida

Versão Original disponível no IPEN

São Paulo

2017 
Dedico a minha vó Lelé, pelos 3 anos de convívio todos os lanches de calabresa acebolada. 


\section{AGRADECIMENTOS}

Aos meus pais, Helvécio Teixeira Filho e Marília Coelho Lopes Teixeira, por me mostrar a importância dos estudos desde pequeno. Só estou aqui por todo esforço e sacrifício de vocês.

A Dra. Barbara Mazzilli, pela paciência comigo durante todo processo, por me estimular a sempre melhorar como pesquisador.

A Dra. Cátia Saueia e Dr. Marcelo Bessa por toda ajuda no laboratório, apoio e conselhos durante as reuniões sobre este trabalho.

Ao Dr. Rubens Figueira, do Instituto Oceanográfico da USP, por ceder as amostras de sedimento utilizadas neste trabalho.

A Dra. Maria Helena Taddei, Sandra Santos e Msc. Mychelle Rosa do Laboratório de Poços de Caldas da CNEN, pela recepção e atenção durante o período que me treinaram nos métodos aplicados neste trabalho.

Ao Instituto de Pesquisas Energéticas e Nucleares pela oportunidade de fazer este trabalho.

A minha esposa, Amanda, pelos incentivos, pela compreensão durante este período corrido e por todos seus sorrisos quando me despedia para ir trabalhar (mesmo, às vezes, você não se lembrando).

Ao meu irmão, Helvécio, pelos momentos de descontração e companheirismo durante o período que moramos junto em São Paulo. Saudades das noites dando risada a cada partida de PES.

Agradeço aos amigos de trabalho Brigitte, Madu, Marcos, Paulo Rene, e Sandra por todo apoio e cooperação durante este período e pelas conversas esclarecedoras sobre o mundo acadêmico.

A Fernanda Cavalcante pelos bolos, bate-papos descontraídos, conversas sérias e companhia agradável durante meu primeiro congresso.

As amigas Camila Cazula e Carolina Fernanda pelas palavras de apoio, momentos de descontração e pelo par de meias de aniversário. Alegra-me muito lembrar que Barcelona fez calor e que Maresias não. 
A Bruna Castilho pelo apoio no laboratório e ajuda com a operação do micro-ondas.

A tantos outros companheiros desta jornada, como bolsistas (com bolsa e sem bolsa), colegas de sala de aula, companheiros da hora do café, e camaradas que dividiram o laboratório. Seja durante a troca de poucas palavras ou por longos períodos de trabalho em conjunto, todos tem uma contribuição importante neste trabalho. 
"Ah não... a luz caiu de novo!"

Trabalhadores do Laboratório de Radiometria Ambiental. 


\title{
DETERMINAÇÃO DOS RADIONUCLÍDEOS NATURAIS URÂNIO E TÓRIO NOS SEDIMENTOS SUPERFICIAIS DO SISTEMA CANANÉIA-IGUAPE
}

\author{
Luiz Flávio Lopes Teixeira
}

\section{RESUMO}

O sistema Cananéia-Iguape é um grande complexo de canais lagunares e estuarinos, localizado no sul do estado de São Paulo. Este sistema passou a receber as águas do rio Ribeira de Iguape após a abertura do canal do Valo Grande, finalizado no ano de 1852. Este canal tornou-se a principal rota de transporte das produções da região do Vale do Ribeira, e nas décadas de 1940 a 1990 as atividades de mineração da região contaminaram o rio Riberia de Iguape, causando alterações nas características originais do sistema Cananéia-Iguape. Este estudo avaliou os níveis de urânio e tório nas amostras de sedimentos superficiais deste sistema. Esta avaliação foi feita através de um método espectrofotométrico utilizando Arsenazo III. As amostras foram digeridas em um forno micro-ondas com aplicação de $\mathrm{HNO}_{3}, \mathrm{HF}$ e $\mathrm{H}_{2} \mathrm{O}_{2}$. As concentrações de urânio variam de $1,3 \mathrm{mg} \cdot \mathrm{kg}^{-1}$ a $5,8 \mathrm{mg} \cdot \mathrm{kg}^{-1} \mathrm{e}$ as de tório de $0,82 \mathrm{mg} \cdot \mathrm{kg}^{-1}$ a $12,1 \mathrm{mg} \cdot \mathrm{kg}^{-1}$. Estes resultados foram comparados com os dados da região, e observou-se que as concentrações determinadas são similares. $O$ índice de geoacumulação foi calculado, classificando a região como "Não contaminada a moderadamente contaminada" para urânio e "Não contaminada" para tório, indicando que não há contaminação por estes metais. Estes resultados podem ser considerados como a concentração basal da região. As avaliações estatísticas identificaram uma maior afinidade do urânio e do tório com a fração de argila e silte. As concentrações de $U$ e Th não apresentaram um comportamento homogêneo ao longo do sistema estudado. 


\title{
DETERMINATION OF URANIUM AND THORIUM NATURAL RADIONUCLIDES IN SEDIMENTS FROM CANANÉIA-IGUAPE SYSTEM
}

\author{
Luiz Flávio Lopes Teixeira
}

\begin{abstract}
The Cananéia-Iguape system is a huge complex of lagoon and estuarine channels, located in the south of São Paulo State. This system received the waters of Ribeira de Iguape River, after the construction of the Valo Grande Channel, an artificial channel which was concluded in 1852. This channel became an important route of transportation of the agricultural production from Ribeira Valley, reducing the transportation time and cost. From 1940 and 1990, the mining activities of the region contaminated the waters from Ribeira de Iguape River, changing the original characteristic of the Cananéia-Iguape system. This study evaluated the uranium and thorium concentration in superficial sediments samples from Cananéia-Iguape system. The evaluation was performed by a spectrophotometric method with Arsenazo III. The samples were digested with $\mathrm{HNO}_{3}, \mathrm{HF}$ and $\mathrm{H}_{2} \mathrm{O}_{2}$, on a microwave. The concentration of uranium varied between $1.3 \mathrm{mg} \cdot \mathrm{kg}^{-1}$ and $5.8 \mathrm{mg} \cdot \mathrm{kg}^{-1}$, and thorium concentration varied between $0.82 \mathrm{mg} \cdot \mathrm{kg}^{-1}$ and $12.1 \mathrm{mg} \cdot \mathrm{kg}^{-1}$. The results obtained were compared with literature values and were very similar. The geo-accumulation index was applied, and the region was classified as "No contaminated or moderately contaminated" for uranium and "No contaminated" for Th; indicating that the region is not contaminated by these elements. The results obtained can be considered as the baseline of the region. The statistical treatment of the results showed that $U$ and Th presented a good correlation with the fraction clay and silt. The concentrations of $U$ and Th did not present a homogeneous behavior along the system studied.
\end{abstract}




\section{SUMÁRIO}

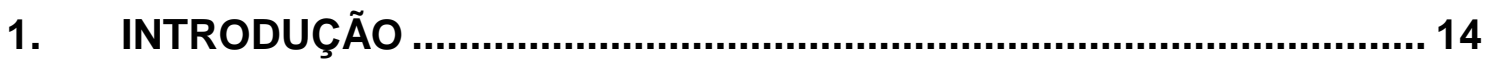

1.1. Materiais radioativos de ocorrência natural ......................................... 14

1.2. Comportamento dos radionuclídeos naturais no meio ambiente............. 17

1.3. Aumento da radioatividade natural decorrente da atividade humana ..... 18

1.4. Comportamento do urânio e tório no meio ambiente.............................. 20

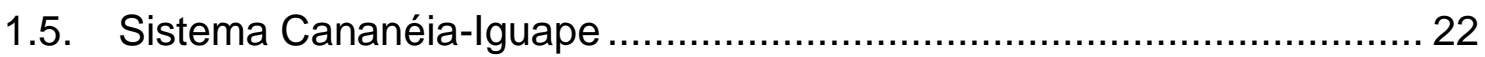

1.6. Técnicas analíticas para determinação de urânio e tório ........................29

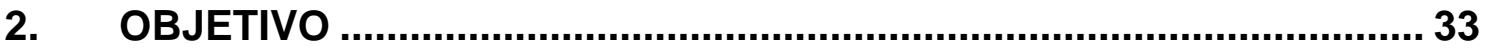

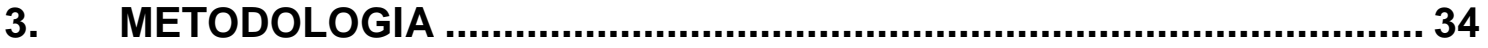

3.1. Coleta de amostras de sedimento do sistema Cananéia-Iguape ........... 34

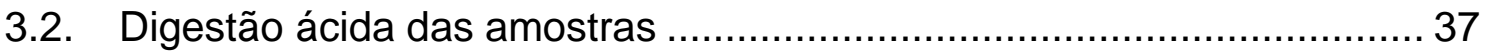

3.3. Determinação de urânio por espectrofotometria..................................... 37

3.4. Determinação de tório por espectrofotometria ..................................... 39

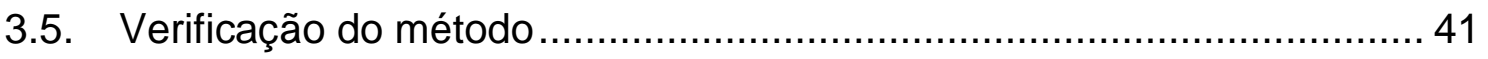

3.5.1. Limite de detecção e limite de quantificação ....................................... 41

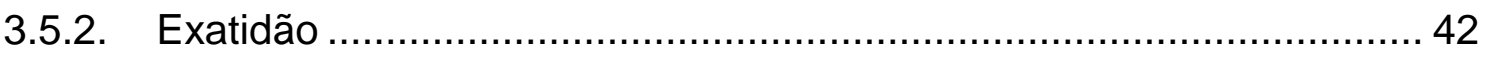

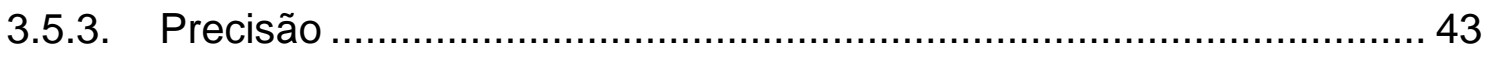

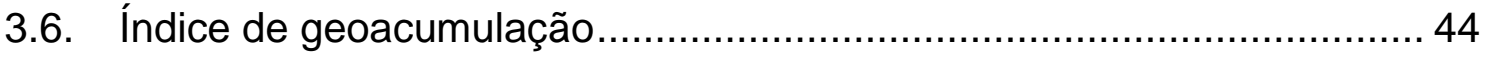

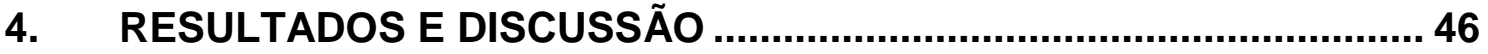

4.1. Método de determinação de urânio ................................................... 46

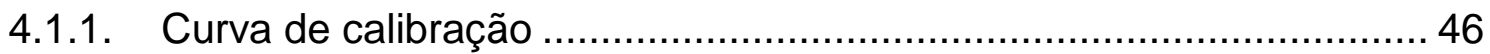

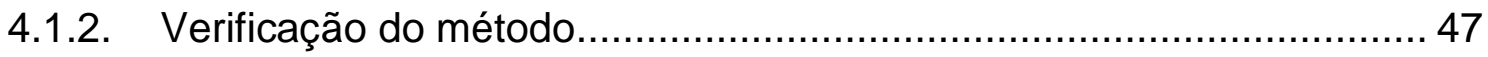

4.2. Método de determinação de tório …………….................................. 49

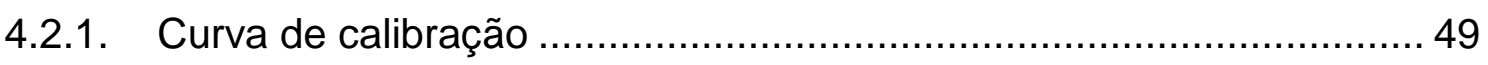

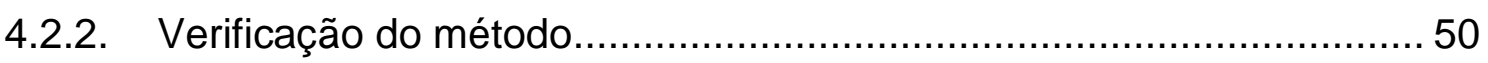


4.3. Determinação da concentração de urânio e tório nos sedimentos do sistema Cananéia-Iguape .............................................................. 52

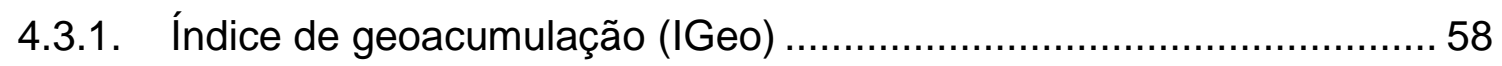

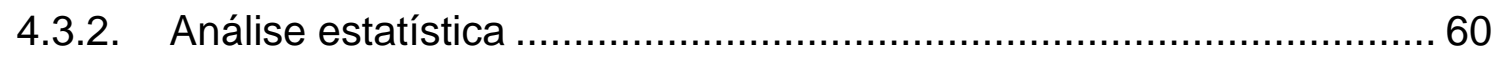

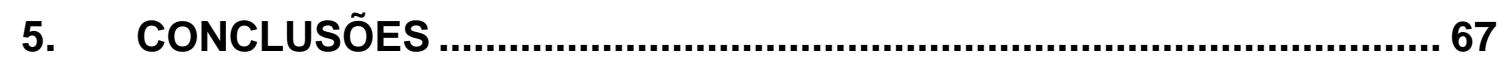

REFERÊNCIAS BIBLIOGRÁFICAS ....................................................... 69

APÊNDICE A - RESULTADOS DAS DETERMINAÇÕES DE URÂNIO......... 74

APÊNDICE B - RESULTADOS DAS DETERMINAÇÕES DE TÓRIO ........... 76 


\section{LISTA DE FIGURAS}

FIGURA 1 - Dose média anual decorrente de fontes de radiação natural.

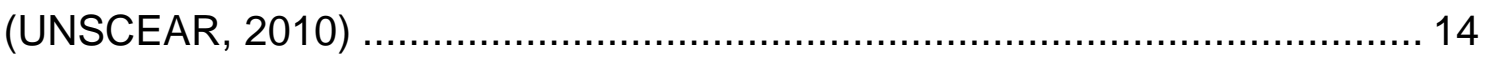

FIGURA 2 - Série de decaimento radioativo do ${ }^{238} \mathrm{U}$....................................... 16

FIGURA 3 - Série de decaimento radioativo do ${ }^{232}$ Th ................................... 16

FIGURA 4 - Principais vias de transferência do urânio e tório nos

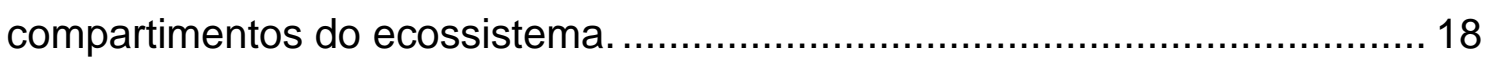

FIGURA 5 - Localização da área de estudo, sistema Cananéia-Iguape. ......... 23

FIGURA 6 - Localização do canal Valo Grande. ......................................... 24

FIGURA 7 - Localização das amostras de sedimento superficial coletadas no

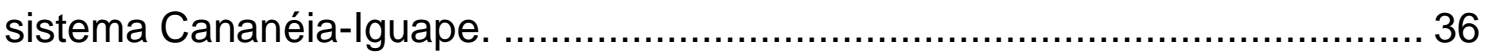

FIGURA 8 - Curva de calibração da determinação de urânio........................... 47

FIGURA 9 - Curva de calibração da determinação de tório. ............................ 50

FIGURA 10 - Concentração e incerteza de urânio $\left(\mathrm{mg} \cdot \mathrm{kg}^{-1}\right)$ nas amostras de sedimento superficial do sistema Cananéia-Iguape...................................... 52

FIGURA 11 - Concentração e incerteza de tório $\left(\mathrm{mg} \cdot \mathrm{kg}^{-1}\right)$ nas amostras de sedimento superficial do sistema Cananéia-Iguape....................................... 53

FIGURA 12 - Distribuição da concentração de urânio no sistema CananéiaIguape.

FIGURA 13 - Distribuição da concentração de tório no sistema CananéiaIguape. 54

FIGURA 14 - Comparação da concentração de urânio determinada em diversos estudos de sedimentos superficiais. Representação da concentração média, máxima e mínima determinada em cada estudo.

FIGURA 15 - Comparação da concentração de tório determinada em diversos estudos de sedimentos superficiais. Representação da concentração média, máxima e mínima determinada em cada estudo.

FIGURA 16 - Índice de geoacumulação (IGeo) de urânio das amostras do sistema Cananeia-lguape 58

FIGURA 17 - Índice de geoacumulação (IGeo) de tório das amostras do sistema Cananeia-Iguape 59 
FIGURA 18 - Gráfico ACP: Dispersão dos "scores" em função do CP1 e CP2, e os autovetores calculados para cada parâmetro. 63 FIGURA 19 - Dendrograma agrupando os resultados obtidos para cada parâmetro em todas as amostras analisadas. 64 FIGURA 20 - Dendrograma agrupando as amostras em função dos parâmetros analisados 65 FIGURA 21 - Distribuição dos grupos, determinados pelo dendrograma de agrupamento, no sistema Cananéia-Iguape. 66 


\section{LISTA DE TABELAS}

TABELA 1 - Concentração de urânio e tório em amostras de sedimento superficial publicados em estudos nas regiões de Cananéia e Baixada Santista.

TABELA 2 - Coordenadas das amostras de sedimento superficial coletadas no sistema Cananéia-lguape

TABELA 3 - Preparo dos reagentes utilizados na determinação de urânio por espectrofotometria. 38

TABELA 4 - Preparo dos reagentes utilizados na determinação de tório por espectrofotometria

TABELA 5 - Classificação do índice de geoaculumação. 45

TABELA 6 - Resultados das análises de cinco alíquotas diferentes da solução diluída de urânio para a confecção da curva de calibração. 46

TABELA 7 - Determinação do LD e LQ da determinação de urânio. 48 TABELA 8 - Resultados da análise do MRC IAEA-SL-1 e cálculo da exatidão e precisão 48

TABELA 9 - Resultados das análises de cinco alíquotas diferentes da solução diluída de tório para a confecção da curva de calibração. 49

TABELA 10 - Determinação do LD e LQ da determinação de tório. 51

TABELA 11 - Resultados da análise do MRC IAEA-SL-3 e cálculo da exatidão e precisão. 51

TABELA 12 - Matriz de correlação de Pearson. 61

TABELA 13 - Coeficientes de correlação das componentes principais e sua porcentagem de variância. 62 


\section{Introdução}

\subsection{Materiais radioativos de ocorrência natural}

Seres vivos estão expostos à radiação ionizante desde os primórdios da Terra. Estas exposições podem ser classificadas segundo os tipos de fonte de radiação ionizante: As fontes naturais, que representam $80 \%$ da dose média anual a qual os seres humanos estão expostos, e as fontes artificiais (UNSCEAR, 2010). As fontes naturais podem ser classificadas como fontes terrestres, representadas pelos radionuclídeos primordiais presentes na Terra desde a sua formação, ou como fontes cósmicas, representadas pela radiação cósmica proveniente do espaço e pelos radionuclídeos formados pela sua interação com a atmosfera da Terra (radionuclídeos cosmogênicos). A FIG. 1 representa como se distribui a dose média anual das fontes naturais existentes.

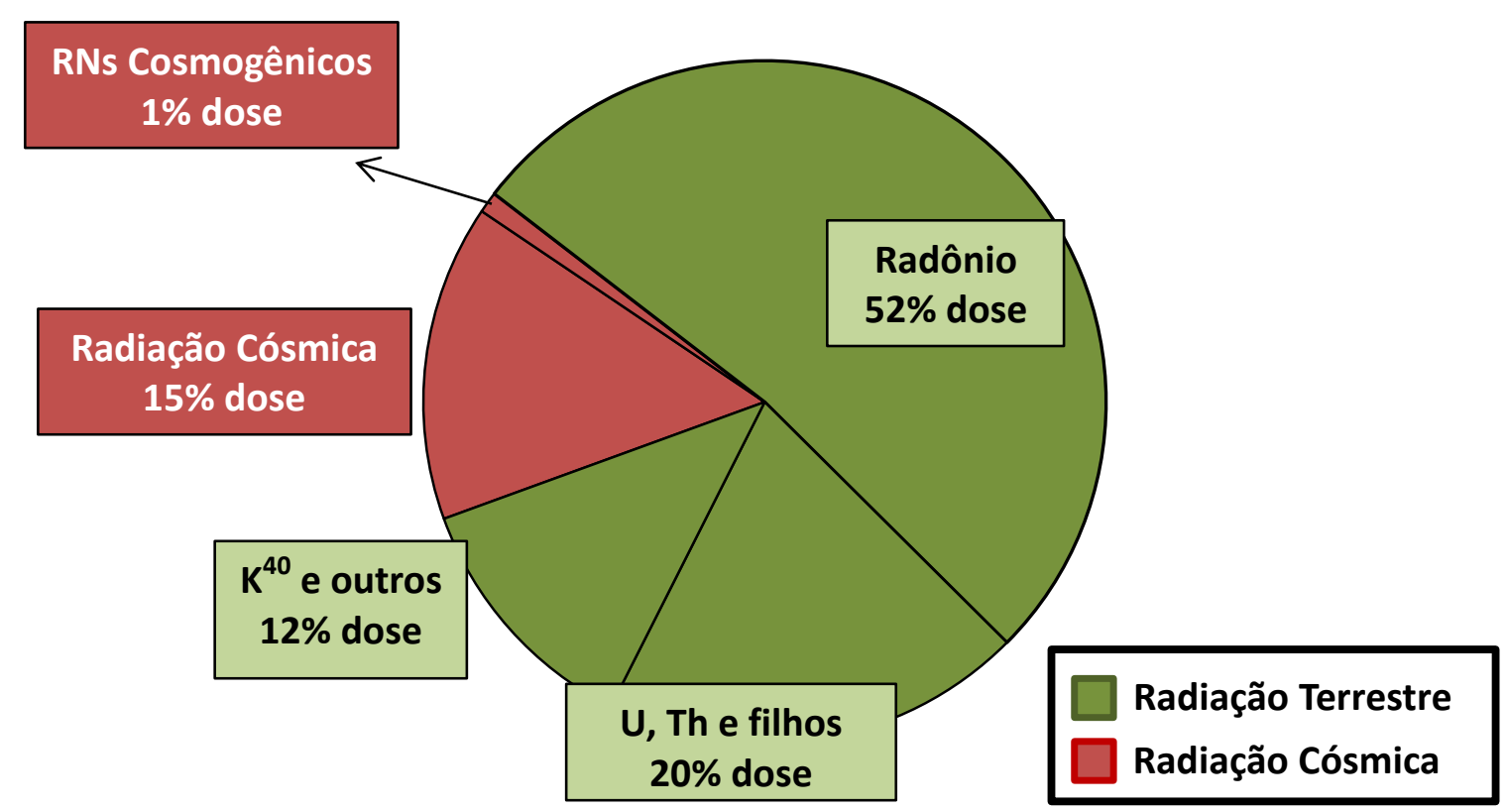

FIGURA 1 - Dose média anual decorrente de fontes de radiação natural.

(UNSCEAR, 2010)

Do ponto de vista da radioproteção, o urânio, tório e seus respectivos filhos são os radionuclídeos primordiais de maior importância, uma vez que são responsáveis por $70 \%$ da dose a qual os seres humanos estão expostos. Por isto é importante conhecer os radionuclídeos formados durante o processo de decaimento do urânio e tório e seu comportamento físico e químico, para então 
entender seu impacto na dose. Na FIG. 2 está representada a série de decaimento do ${ }^{238} \mathrm{U}$, o isótopo de urânio mais abundante encontrado na natureza. Já na FIG. 3 está representada a série de decaimento do ${ }^{232} \mathrm{Th}$, praticamente o único isótopo de tório presente na natureza. Das duas séries de decaimento podemos destacar os seguintes radionuclídeos:

- ${ }^{226} \mathrm{Ra}$ e ${ }^{228} \mathrm{Ra}$ : Apresentam comportamento químico, tanto na natureza como no corpo humano, semelhante ao cálcio. Isto permite que se acumulem nos ossos dos seres vivos, causando exposição interna (Mazzilli et al., 2013). Esta exposição é significativa por causa do longo tempo de meia vida, respectivamente, 1600 anos e 5,75 anos.

- ${ }^{222} \mathrm{Rn}$ e ${ }^{220} \mathrm{Rn}$ : São gases que possuem tempo de meia vida, respectivamente, de 3,82 dias e 55,6s. Eles emanam dos solos e rochas e são dispersos na atmosfera. Com isto ao serem inalados sofrem decaimento radioativo dentro do pulmão, o que possibilita 0 acúmulo de seus filhos neste órgão. Isso pode induzir a formação de câncer devido o aumento da irradiação interna (Mazzilli et al., 2013).

- ${ }^{210} \mathrm{~Pb}$ : É formado na atmosfera e litosfera a partir do decaimento do ${ }^{222} \mathrm{Rn}$, cujo os filhos possuem tempo de meia vida curto. Com isto, o ${ }^{210} \mathrm{~Pb}$ é encontrado disperso na atmosfera, tornando a deposição aérea sua rota de transferência. É absorvido pelo homem principalmente pela inalação, e tende a se acumular nos ossos, rins e fígado (Mazzilli et al., 2013). Como possui tempo de meia de vida 22,3 anos, representa uma perigosa fonte de irradiação interna. 


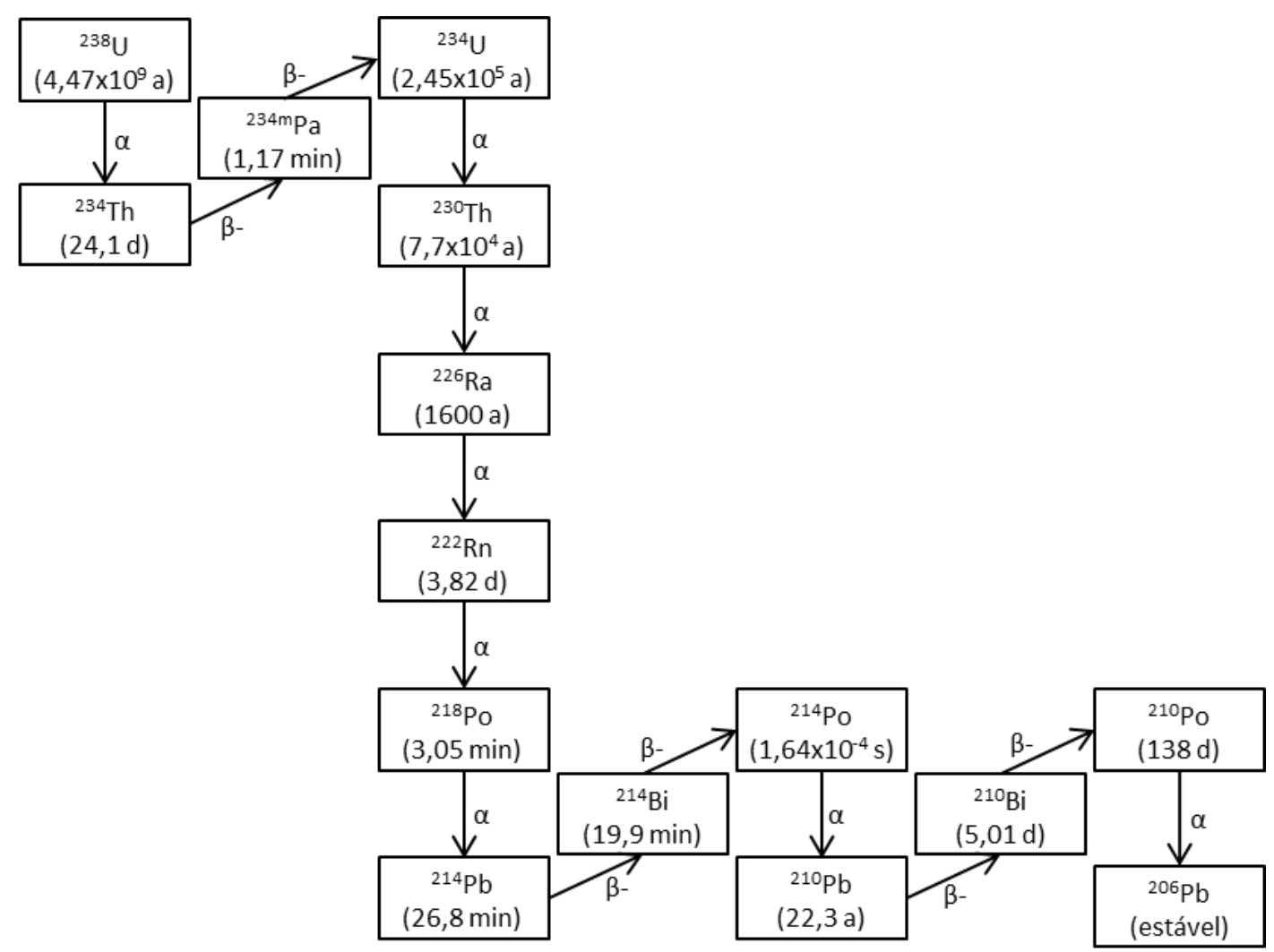

FIGURA 2 - Série de decaimento radioativo do ${ }^{238} U$

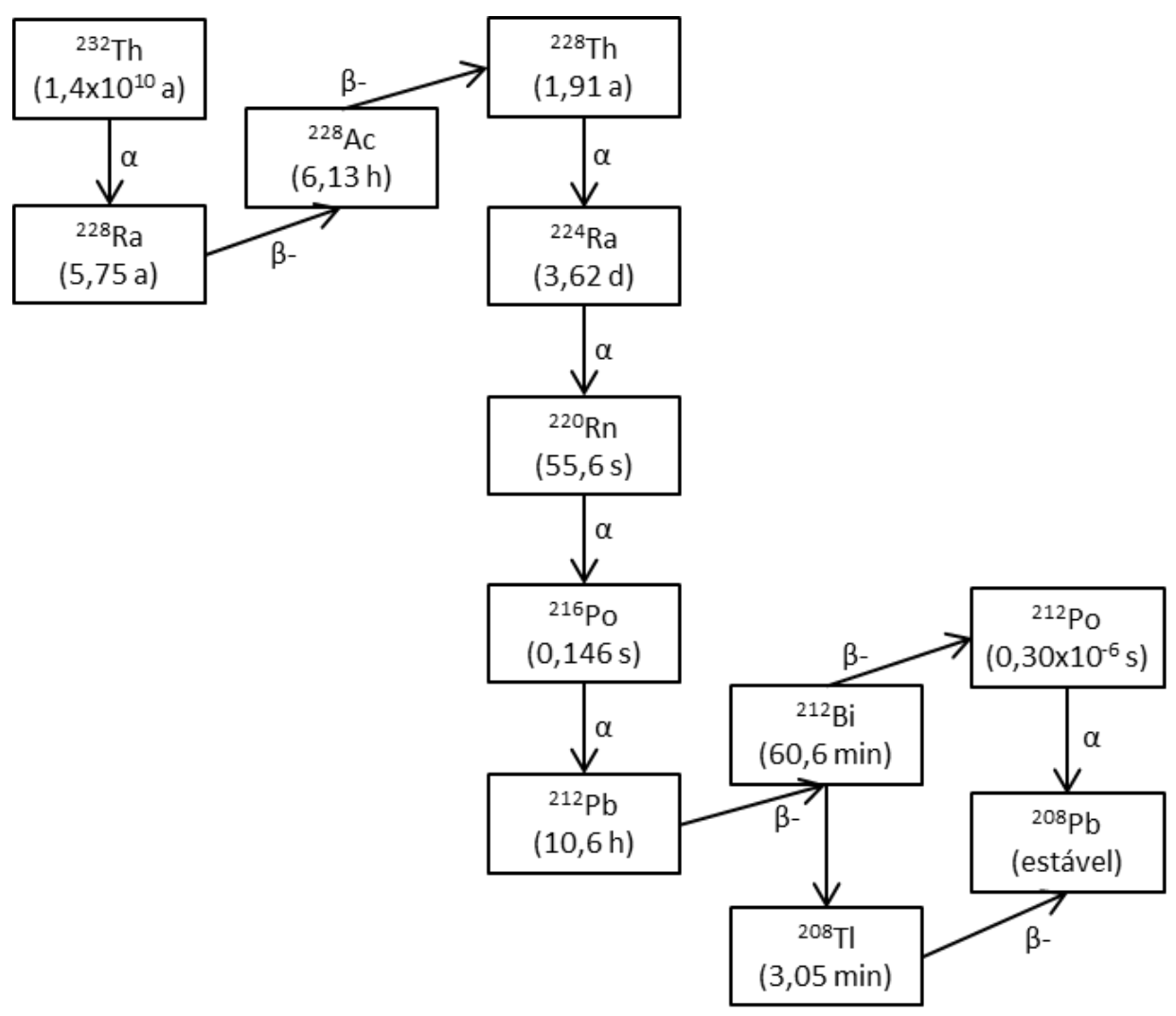

FIGURA 3 - Série de decaimento radioativo do ${ }^{232} \mathrm{Th}$ 


\subsection{Comportamento dos radionuclídeos naturais no meio ambiente}

Quando um radionuclídeo é liberado no meio ambiente, ele pode se deslocar, percorrendo diversos caminhos e mudando de compartimento do meio ambiente. Durante o transporte, o radionuclídeo pode encontrar um ambiente propicio à sua acumulação, seja devido à afinidade com o compartimento ou por impossibilidade de sua transferência Esse tipo de fenômeno pode acarretar num aumento considerável na concentração desse radionuclídeo no compartimento. Este acúmulo tem importância devido aos efeitos da radiação que antes não era existente no compartimento onde ele se acumula. Portanto, é importante determinar o caminho que esses radionuclídeos percorrem na natureza, assim como identificar possíveis acúmulos que possam ser prejudiciais ao homem.

Os radionuclídeos naturais terrestres tiveram sua origem nas rochas. A sua transferência das rochas para o solo, ou então para os sedimentos, se dá principalmente pelo processo de erosão. A FIG. 4 apresenta as principais vias de transferência do urânio e tório no meio ambiente. O urânio e tório presente nas rochas, solo e sedimentos podem ser transferidos para águas, tanto subterrâneas como superficiais, através da lixiviação, e em escala menor para as plantas através da sua absorção em conjunto com outros micronutrientes, dessa forma entrando na cadeia alimentar. A transferência destes radionuclídeos presentes na água subterrânea para o solo ocorre a partir do seu uso na irrigação de lavouras, e sua transferência para plantas e animais ocorre pelo seu consumo. Quando os radionuclídeos urânio e tório encontramse dissolvidos nas águas superficiais, mudanças de salinidade e $\mathrm{pH}$ podem causar sua precipitação e adsorção nos sedimentos, enquanto que o processo de infiltração, responsável por abastecer os aquíferos, transporta os radionuclídeos para as águas subterrâneas (Mazzilli et al., 2013). 


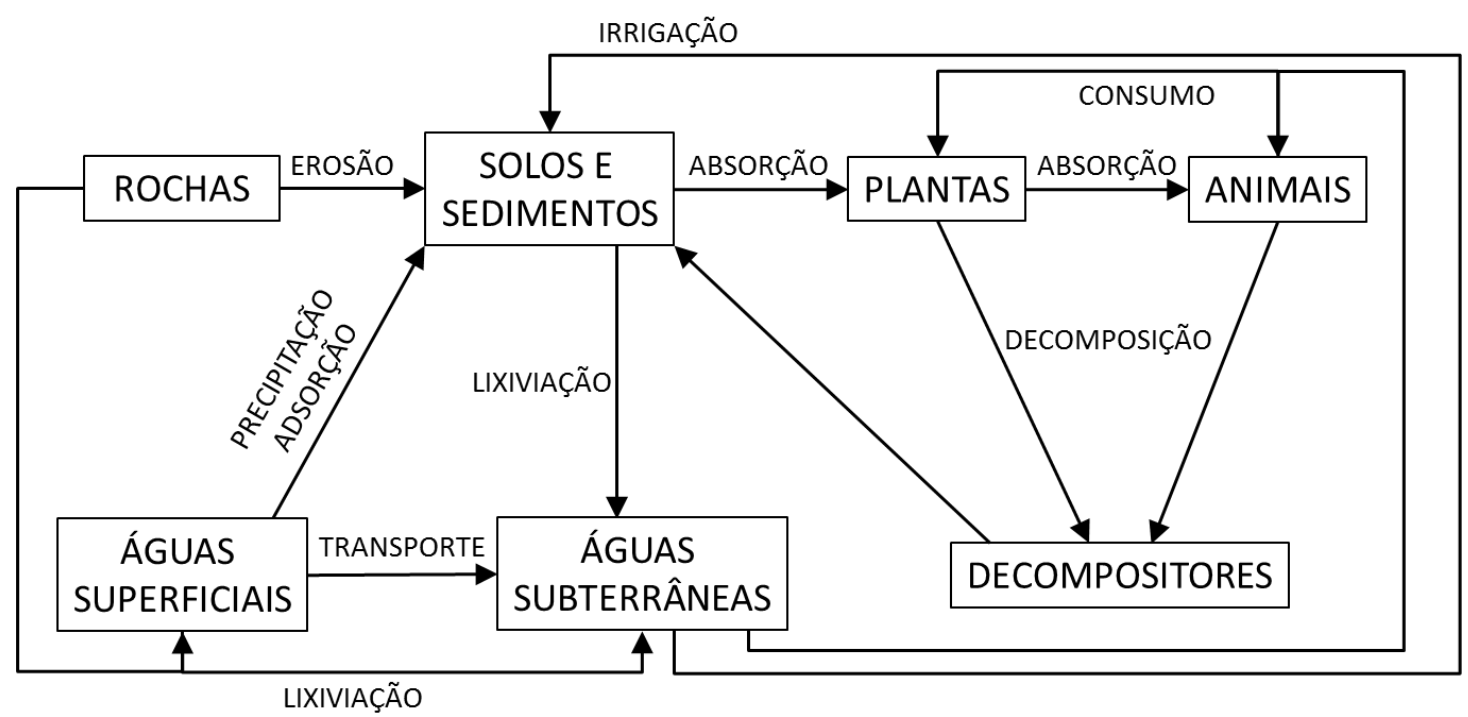

FIGURA 4 - Principais vias de transferência do urânio e tório nos compartimentos do ecossistema.

\subsection{Aumento da radioatividade natural decorrente da atividade humana}

Diversas atividades humanas podem liberar urânio e tório para o meio ambiente, alterando o ciclo natural de deslocamento desses elementos e, eventualmente, aumentando a concentração em compartimentos específicos. Isto pode causar um aumento no nível de radiação do compartimento, o que pode acarretar em exposições prejudiciais. Entre as diversas atividades humanas que podem liberar estes radionuclídeos se destacam as indústrias de mineração. Os processos de mineração utilizam como matéria-prima rochas, que por sua vez podem conter urânio e tório em sua composição. Quando a matéria-prima é submetida a processos físicos ou químicos para a extração de minérios pode ocorrer à concentração dos radionuclídeos nos produtos do processo, subprodutos ou até mesmo nos rejeitos. Estes materiais enriquecidos de radionuclídeos são chamados de Naturally Occurring Radioactive Material, NORM. Com isto tornou-se necessário o estabelecimento de normas reguladoras para as indústrias cuja atividade possa produzir NORM. No Brasil, a Comissão Nacional de Energia Nuclear (CNEN) é a autarquia responsável por estabelecer normas e regulamentos em radioproteção, assim como realizar sua fiscalização. Dentre as diversas normas estabelecidas pela CNEN, podemos destacar CNEN-NN-4.01 "Requisitos de segurança e proteção 
radiológica para instalações mínero-industriais" e CNEN-NN-3.01 "Diretrizes básicas de proteção radiológica" quando se trata de assuntos referentes à NORM e as indústrias de mineração.

A norma "Requisitos de segurança e proteção radiológica para instalações mínero-industriais" (CNEN-NN-4.01, 2005) é aplicável a instalações minero-industriais que manipulam, processam ou armazenam minérios, rejeitos, escórias ou resíduos que apresentem em sua composição radionuclídeos naturais da série do urânio e do tório, onde estes materiais possam causar exposição de maneira indevida a indivíduos do público ou trabalhadores, permitindo sua exposição à radiação ionizante. A norma contempla tanto instalações em operação como instalações suspensas ou ainda aquelas que tenham cessado sua atividade. Ela classifica a indústria segundo a concentração de atividade específica dos materiais que ela manipula. Conforme a classificação da indústria nesta norma ela torna-se passível de controle da CNEN, tendo que atender aos requisitos da norma "Diretrizes básicas de proteção radiológica" (CNEN-NN-3.01, 2014).

A norma "Diretrizes básicas de proteção radiológica" (CNEN-NN-3.01, 2014) e suas posições regulatórias têm como principal objetivo estabelecer os requisitos básicos de proteção radiológica das pessoas em relação à exposição à radiação ionizante. Esta norma é aplicável às práticas que envolvam atividades que possam envolver exposição à radiação emitida por fontes radioativas ou materiais radioativos, assim como a atividades envolvendo exposição a fontes naturais quando a CNEN considerar necessário seu controle. Ela contempla exposições ocupacionais, exposições médicas e exposições do público, seja em situações de exposições normais ou potenciais. Estabelece todos os requisitos para práticas e para intervenção que devem ser seguidos para início, a manutenção e o encerramento de atividades sobre o controle desta norma.

Portanto, torna-se importante a determinação dos níveis de concentração de atividade dos radionuclídeos naturais no meio ambiente, na área de influência de instalações minero-industriais. Como estas instalações normalmente liberam seus efluentes líquidos em rios, o urânio e tório presentes tendem a se agregar nos sedimentos por adsorção e precipitação. Portanto, é 
importante determinar os níveis basais destes elementos no sedimento para se avaliar possíveis impactos.

\subsection{Comportamento do urânio e tório no meio ambiente}

O urânio e tório são elementos que fazem parte da série dos actinídeos, e diferentemente dos demais elementos da série podem ser encontrados e extraídos em grandes quantidades na natureza. O tório pode ser encontrado nas areias monazíticas na forma de fosfatos ou então na torita, $\mathrm{ThSiO}_{4}$. A principal fonte de urânio é a uraninita, principalmente na forma de $\cup_{2}$. $\mathrm{O}$ estado de oxidação mais estável do tório é +4 e do urânio +6 , pois neste estado ocorre o envolvimento de todos os elétrons externos nas ligações, e eles ainda podem apresentar outros estados diferentes. Ambos apresentam ponto de fusão elevado, acima de $1100^{\circ} \mathrm{C}$ (Lee, 1980).

O estudo minucioso da química do urânio iniciou após a descoberta de sua fissão em 1939, tornando-o o mais importante combustível nuclear. Seus minérios se apresentam em forma de óxidos e vanadatos, sendo mais abundante que alguns elementos de uso comum, como prata e o cádmio. $O$ urânio natural apesenta três isótopos: $99,3 \%$ de ${ }^{238} \mathrm{U}, 0,7 \%$ de ${ }^{235} \mathrm{U}$ e traços de ${ }^{234} U$, sendo $\circ{ }^{235} U$ o de maior importância para produção de combustível nuclear. O urânio apresenta os estados de oxidação 2+, 3+, 4+, 5+ e 6+, sendo os estados de oxidação 4+ e 6+ os que mais aparecem na natureza. É um metal muito reativo que se dissolve em ácidos, e reage com oxigênio, halogênios e hidrogênio e outros elementos (Lee, 1980).

Seu comportamento geoquímico apresenta características diferentes dos outros metais. O urânio é altamente solúvel em ácidos fortes e em águas oxidantes contendo resíduos ácidos de processos de mineração. Nestas condições, o urânio encontra-se em solução como cátion $\mathrm{UO}_{2}{ }^{2+}$, onde o urânio apresenta o estado de oxidação $6+$, e em pequenas porções na forma do cátion $\mathrm{UO}_{2} \mathrm{~F}^{+}$. Já quando o meio apresenta condições neutras ou alcalinas oxidantes, ocorre a predominância do complexo solúvel $\mathrm{UO}_{2}\left(\mathrm{CO}_{3}\right)_{2}{ }^{2-}$. Quando as condições do meio são redutoras, formam-se o óxido insolúvel $\mathrm{UO}_{2}$, compostos de urânio no estado de oxidação 4+, e diversos outros óxidos, como 
$\mathrm{U}_{3} \mathrm{O}_{8}$. A redução do $U^{6+}$ a $U^{4+}$ ocorre pela ação de bactérias redutoras de sulfatos e de ferro, sendo que este processo ocorre, geralmente, em sedimentos anóxicos (De Vos et. al, 2006).

A mobilidade do urânio no solo é dependente da formação do cátion $\mathrm{UO}_{2}{ }^{2+}$, uma vez que este cátion é solúvel em diversas faixas do $\mathrm{pH}$ do solo. $\mathrm{A}$ solubilidade do urânio no solo pode ser aumentando pela ação de ácidos orgânicos, entretanto esses ácidos interferem na sua mobilidade ao permitirem a formação de precipitados pouco solúveis, por exemplo, na forma de fosfatos e óxidos. Estas condições também permitem que o urânio seja adsorvido pela fração de argila e pela presença de matéria orgânica. Quando o urânio está dissolvido na água ele se associa fortemente com a matéria orgânica, com óxido de ferro e com os fosfatos dissolvidos. Em pequenas quantidades, o urânio dissolvido sofre co-precipitação junto do cálcio, do chumbo e de alguns óxidos secundários de ferro. Quando na presença de sílica dissolvida, o urânio precipita na forma de confinita, USiO4, e na presença de vanádio ele complexa na forma de carnotita, um mineral de baixa solubilidade (De Vos et. al, 2006).

O tório é encontrado principalmente nas areias monazíticas, onde podem apresentar concentrações de até $30 \%$ na forma de fosfatos misturados com fosfatos de lantanídios. É utilizado na indústria, na forma de dióxido de tório, $\mathrm{ThO}_{2}$, na fabricação de camisas incandescentes de lâmpadas a gás. Naturalmente, apresenta apenas 0 isótopo ${ }^{232} \mathrm{Th}$, que embora não seja fissionável pode ser submetido a uma reação $(n, \gamma)$ para alimentar reatores do tipo breeder. $\mathrm{O} \mathrm{ThO}_{2}$ é praticamente inerte a qualquer reagente, dissolvendo-se apenas numa mistura de $\mathrm{HNO}_{3}$ e $\mathrm{HF}$. O tório é encontrado na natureza no estado de oxidação 4+. O íon $\mathrm{Th}^{4+}$ pode ser encontrado tanto no estado sólido como em solução (Lee, 1980).

Do ponto de vista da geoquímica, o tório apresenta comportamento semelhante ao urânio, podendo substituir elementos terras-raras em alguns minerais, assim com se associar à apatita e ao esfeno (Kabata-Pendias, 2000). A mobilidade do tório é dependente da formação do $\mathrm{Th}^{4+}$, pois a solubilidade deste cátion, numa faixa ampla de $\mathrm{pH}$ dos solos, é responsável por seu deslocamento. Assim como o urânio, a solubilidade do tório aumenta quando na presença de ácidos orgânicos, contudo sua 
mobilidade é prejudicada devido à sua precipitação, por exemplo, na forma de fosfatos e óxidos, assim como também pela sua adsorção pela fração de argila e matéria orgânica presente no solo. Nas condições ambientais, o tório apresenta baixa mobilidade, pois o $\mathrm{ThO}_{2}$ é muito estável e pouco solúvel. Os agentes carregadores do tório, como a monazita, também são muito estáveis, dificultando sua mobilidade. O Th( $\left(\mathrm{SO}_{4}\right)^{2+}$ é uma das formas mais solúveis do tório na natureza, e é formado quando o pH é menor do que 3 e em condições oxidantes. Quando o tório encontra-se dissolvido ele é rapidamente sorvido por minerais argilosos ou então são hidrolisados a $\mathrm{Th}(\mathrm{OH})_{4}$, que também se associa aos minerais argilosos. Logo, o tório é praticamente insolúvel em águas de superfície e subterrâneas (De Vos et. al, 2006).

Ainda há de se considerar que o urânio e tório não são elementos estáveis, sofrendo decaimento radioativo natural. Esta característica tem grande importância, pois seus filhos ou possuem comportamento idêntico ao seu correspondente estável ou análogo a elementos pertencentes ao mesmo grupo químico. Com isso, é importante avaliar seu comportamento no meio ambiente, considerando os compartimentos onde se acumulam e como seu tempo de meia de vida pode interferir. Dá série de decaimento natural do ${ }^{238} \mathrm{U}$, os radionuclídeos de destaque são ${ }^{210} \mathrm{~Pb}$, por ter comportamento idêntico ao chumbo estável; ${ }^{226} \mathrm{Ra}$, que possui grande mobilidade entre os compartimentos do ecossistema e comportamento semelhante ao cálcio; o ${ }^{210} \mathrm{Po}$, devido ao seu longo tempo de meia vida e comportamento fisiológico; e o ${ }^{222} \mathrm{Rn}$, que se acumula em ambientes fechados e sua inalação permite 0 acumulo de seus produtos de decaimento dentro do organismo. Já na série do ${ }^{232} \mathrm{Th}$, destacamse ${ }^{228} \mathrm{Ra}$ e ${ }^{220} \mathrm{Rn}$, pelos mesmos motivos apresentados anteriormente (Mazzilli et al. 2013).

Pode-se concluir que o urânio e o tório, quando liberados no meio ambiente, tendem a se concentrar nos compartimentos solo e sedimento.

\subsection{Sistema Cananéia-Iguape}

O sistema Cananéia-Iguape, representado na FIG. 5, fica localizado no extremo sul do estado de São Paulo (latitudes $24^{\circ} 40^{\prime}$ 'S e $25^{\circ} 05^{\prime}$, longitudes 
$47^{\circ} 25^{\prime} \mathrm{O}$ e $\left.48^{\circ} 00^{\prime} \mathrm{O}\right)$, na divisa com o estado do Paraná. Abrangendo $100 \mathrm{~km}$ de extensão, este sistema é composto por canais em torno da ilha de Cananéia, ilha do Cardoso, ilha Comprida e a cidade de Iguape. Seu clima é subtropical, apresentando umidade relativa do ar próxima de $87 \%$ e com média pluvial anual maior do que $2.248 \mathrm{~mm}$, tendo o período de chuvas entre dezembro e abril e o de estiagem de maio a novembro. As características climáticas e geomorfológicas da região são responsáveis pela existência de restingas e mangues ao longo das margens de corpos de água e pelas dunas de Mata Atlântica nas regiões mais altas (Tramonte, 2014).

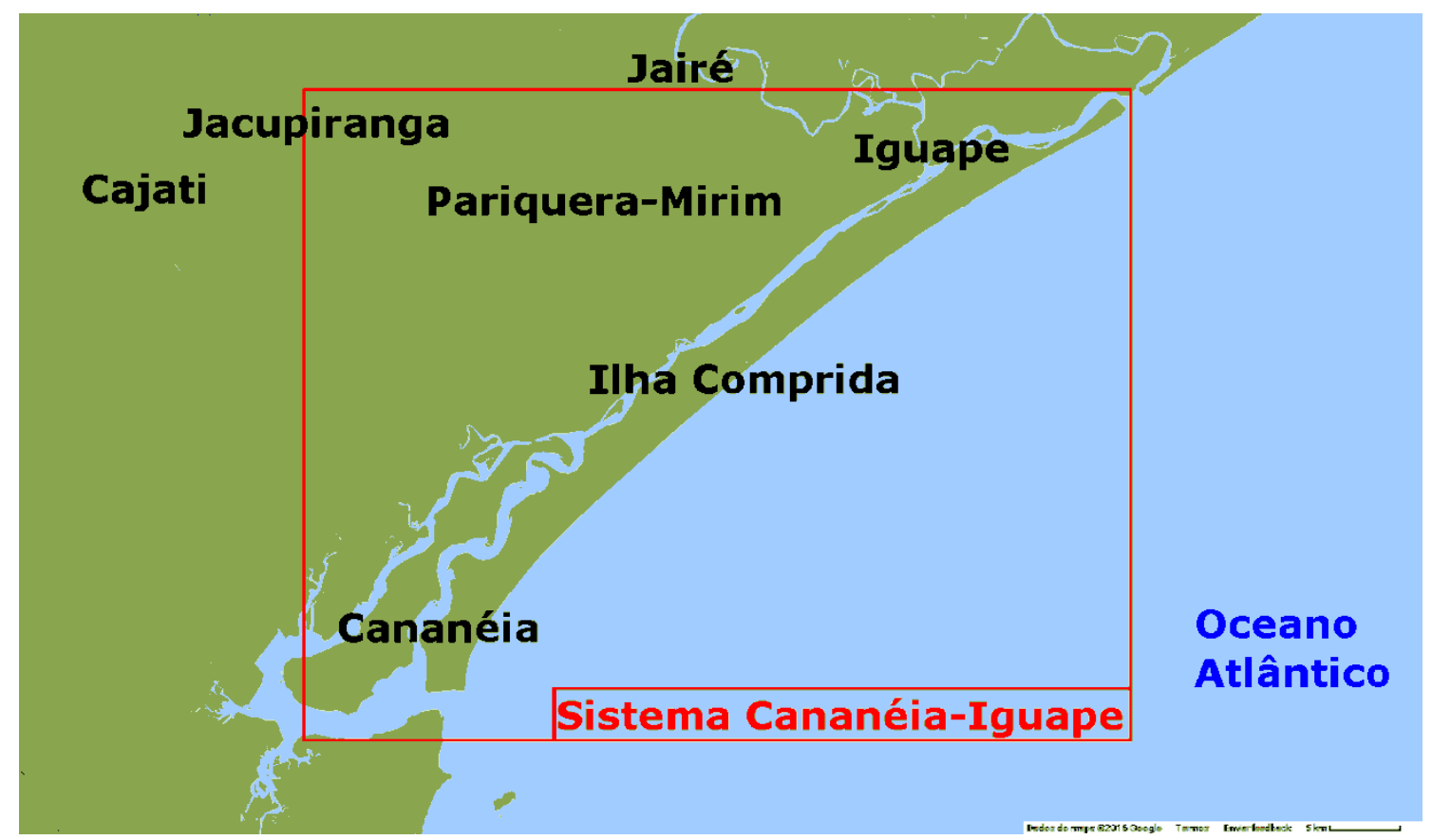

FIGURA 5 - Localização da área de estudo, sistema Cananéia-Iguape.

Com o objetivo de baratear e facilitar o escoamento da produção agrícola da região, principalmente do Vale do Ribeira do Iguape, para o principal porto da região, entre os anos de 1827 e 1852 foi construído o canal artificial Valo Grande, antigamente conhecido como Valo do Rocio. A FIG. 6 apresenta a localização do canal Valo Grande. Inicialmente o canal apresentava 4,4m de largura, mas devido à erosão ao longo dos anos atingiu a marca de $235 \mathrm{~m}$. Este canal possibilitou o desague do rio Ribeira do Iguape no sistema Cananéia-Iguape, alterando as características físico-químicas do 
sistema (Tramonte, 2014). Devido à atividade mineradora, mais intensa até meados da década de 90 (GEOBRÁS apud Tramonte, 2014), na região do Vale do Ribeira, estudos foram feitos para verificar contaminação tanto ao longo do rio Ribeira do Iguape como no sistema Cananéia-Iguape.

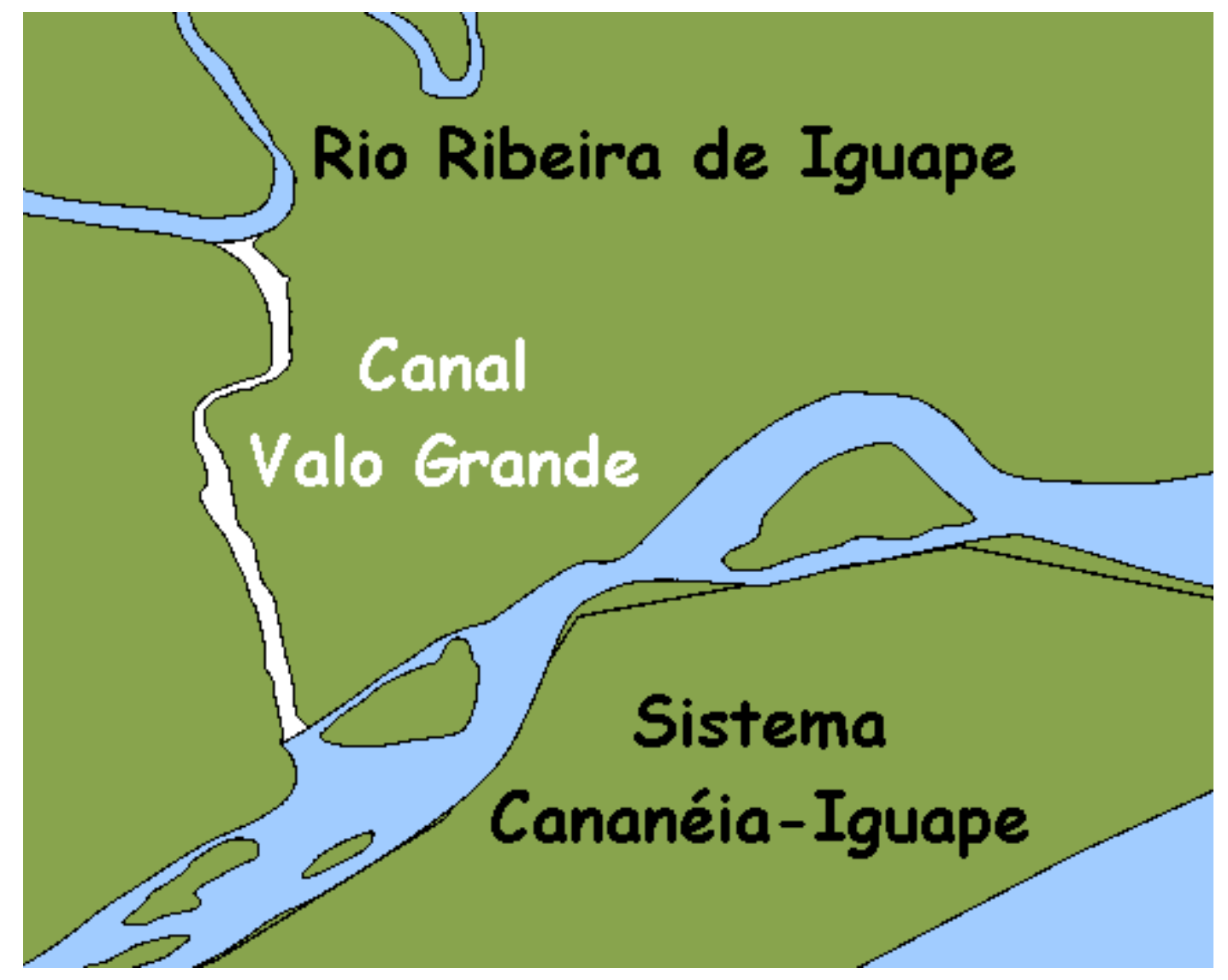

FIGURA 6 - Localização do canal Valo Grande.

Moraes (1997) comparou os resultados das concentrações de chumbo, zinco e cobre determinados em sedimentos coletados pela CETESB, na campanha de fevereiro de 1990, ao longo do Rio Ribeira de lguape e do sistema Cananéia-Iguape com a localização de minas e siderúrgicas de chumbo existentes na região do Vale do Ribeira, e identificou a influência destas indústrias na concentração destes metais ao longo do rio. Seu estudo da razão isotópica de chumbo em sedimentos da mesma região comprovou a hipótese que as atividades das indústrias mineradoras e siderúrgicas na região 
do Alto do Vale do Ribeira são responsáveis pela contaminação na região sistema de Cananéia-Iguape e do rio Ribeira de Iguape.

Silva (1997) avaliou o impacto ambiental do arsênio que a mineração de chumbo e zinco no Vale do Ribeira causou. Amostras de sedimentos de corrente, colunas de sedimentos, águas superficiais e rejeitos de mineração foram analisadas, e os resultados obtidos dos sedimentos de corrente apresentaram concentrações de arsênio além do nível máximo recomendado, sendo que as maiores concentrações foram encontradas nos pontos mais próximos das mineradoras. Já as análises das colunas de sedimentos identificaram contaminação por arsênio nos amostras mais superficiais da coluna, indicando possível interferência antropogênica.

Guimarães e Sígolo (2008) estudaram a contribuição da escória, da fundição de minério de chumbo produzida pela Plumbum S/A, na contaminação do rio Ribeira de Iguape. Amostras da pilha de escória que ficavam depositadas no solo no complexo da Plumbum e sedimentos de suspensão, coletados nas cidades de Eldorado, Sete Barras, Registro e Iguape, foram analisadas. Foi determinada a presença de chumbo, cobre e zinco nos sedimentos em suspensão, indicando que partes desses metais estão se deslocando ao longo do rio até sua foz.

Tramonte et al. (2015) avaliaram a disponibilidade de chumbo, zinco e cobre em amostras de sedimentos do sistema Cananéia-Iguape, determinando teor pseudo-total e o teor nas frações disponíveis. Os resultados indicaram que o teor disponível de zinco e cobre são menores dos que os valores de referência, indicando que efeitos adversos ao ecossistema não são esperados. Entretanto, o chumbo apresentou teor acima dos valores de referência na metade das amostras analisadas. Comparando os resultados do teor pseudo-total com teor nas frações disponíveis, observa-se a seguinte ordem decrescente de mobilidade destes elementos: $\mathrm{Pb} \rightarrow \mathrm{Zn} \rightarrow \mathrm{Cu}$.

Como apresentado por estes trabalhos, há evidenciais de que o rio Ribeira de Iguape sofreu contaminação por metais estáveis decorrente das atividades minero-industriais desenvolvidas durante anos ao longo da região do Vale do Ribeira. Já o sistema Cananéia-Iguape, que recebe as água do rio 
Ribeira de Iguape, apresentou teores acima dos valores de referência para o chumbo.

Existem poucos estudos publicados quando se trata da concentração radionuclídeos, tanto naturais como artificiais, na região. Como já foi discutido anteriormente, atividades de mineração podem ser uma fonte de dispersão de NORM no meio ambiente. Como os estudos a respeito de metais estáveis indicaram contaminação da região devido a atividades minero-industriais, torna-se importante avaliar uma possível contaminação por NORM.

Ferreira et al. (1986) quantificaram ${ }^{40} \mathrm{~K},{ }^{238} \mathrm{U},{ }^{232} \mathrm{Th}$, a produção de calor radiogênico e a condutividade térmica em amostras de sedimentos da plataforma continental do estado de São Paulo e do sistema Cananéia-Iguape. As concentrações médias encontradas nas amostras do sistema CananéiaIguape foram de $1,21 \%$ de ${ }^{40} \mathrm{~K}$ (desvio padrão 0,38\%), 1,75 ppm de urânio equivalente (desvio padrão 0,66 ppm) e de 4,29 ppm de tório equivalente (desvio padrão 2,88 ppm), sendo que a concentração de urânio e tório equivalente foi determinada considerando que as amostras encontravam-se em equilíbrio secular.

Saito et al. (2001) quantificaram ${ }^{210} \mathrm{~Pb},{ }^{226} \mathrm{Ra}$ e ${ }^{137} \mathrm{Cs}$ em três perfis coletados na região do sistema Cananéia-Iguape e na plataforma continental do estado de São Paulo. O objetivo do trabalho foi quantificar esses radionuclídeos em sedimentos e determinar a taxa de sedimentação através do ${ }^{210} \mathrm{~Pb}$ e ${ }^{137} \mathrm{Cs}$. As concentrações determinadas de ${ }^{210} \mathrm{~Pb}$ e ${ }^{226} \mathrm{Ra}$ são consistentes com a literatura, e o ${ }^{137} \mathrm{Cs}$ quantificado é decorrente do processo de fallout, devido aos diversos testes nucleares que espalharam radionuclídeos na atmosfera terrestre. As concentrações de ${ }^{210} \mathrm{~Pb}$ nos perfis do sistema Cananéia-Iguape variaram de $14,3 \mathrm{~Bq} \cdot \mathrm{kg}^{-1}$ a $122,5 \mathrm{~Bq} \cdot \mathrm{kg}^{-1}$, as concentrações de ${ }^{226} \mathrm{Ra}$ de 2,3 Bq. $\mathrm{kg}^{-1}$ a $15,2 \mathrm{~Bq} \cdot \mathrm{kg}^{-1}$ e as de ${ }^{137} \mathrm{Cs}$ de 0,28 Bq$\cdot \mathrm{kg}^{-1} \mathrm{a}$ $2,3 \mathrm{~Bq} \cdot \mathrm{kg}^{-1}$. A taxa de sedimentação determinada através do ${ }^{137} \mathrm{Cs}$ apresentou resultado condizentes com a taxa de sedimentação determinada através do ${ }^{210} \mathrm{~Pb}$.

Em outro trabalho de Saito et al. (2006) mais quatro perfis da região foram analisados, quantificando novamente ${ }^{210} \mathrm{~Pb},{ }^{226} \mathrm{Ra}$ e ${ }^{137} \mathrm{Cs}$ e também os 
metais pesados chumbo, cobre e zinco. As concentrações de ${ }^{210} \mathrm{~Pb}$ determinadas nos perfis variaram de $6,1 \mathrm{~Bq} \cdot \mathrm{kg}^{-1}$ a $167 \mathrm{~Bq} \cdot \mathrm{kg}^{-1}$, e as concentrações de ${ }^{137} \mathrm{Cs}$ variaram de $0,28 \mathrm{~Bq} \cdot \mathrm{kg}^{-1}$ a $6,1 \mathrm{~Bq} \cdot \mathrm{kg}^{-1}$. As taxas de sedimentação determinadas pela medida do ${ }^{210} \mathrm{~Pb}$ e ${ }^{137} \mathrm{Cs}$ apresentaram resultados concordantes.

Armelin e Saiki (2009) utilizaram análise por ativação neutrônica instrumental (INAA) para caracterizar um testemunho, com profundidade de $200 \mathrm{~cm}$, coletado na costa sul do estado de São Paulo, na região da ilha de Cananéia. Os resultados obtidos para vários elementos quantificados, entre eles urânio e tório, apresentaram uma queda abrupta da concentração a partir da camada de 132-134 cm. Esta alteração pode ser relacionada com interferências antrópicas durante a formação desta camada de sedimentos, podendo ter relação com a abertura do canal de Valo Grande. A concentração média de urânio determinada entre as camadas de 0-2 cm até $122-124 \mathrm{~cm}$ do testemunho foi de $3,8 \mathrm{mg} \cdot \mathrm{kg}^{-1}$, e a concentração média de tório de $13,2 \mathrm{mg} \cdot \mathrm{kg}^{-1}$. A partir da camada de $132-134 \mathrm{~cm}$ até o fim do testemunho a concentração média de urânio determinada foi de $1,9 \mathrm{mg} \cdot \mathrm{kg}^{-1}$ e de tório de $3,3 \mathrm{mg} \cdot \mathrm{kg}^{-1}$.

Damato (2010) determinou a concentração de radionuclídeos da série do ${ }^{238} \mathrm{U}$ e ${ }^{232} \mathrm{Th}$, elementos traços e elementos maiores em perfis de sedimentos do estuário de Santos-Cubatão, estuário de São Vicente, canal de Bertioga e baia de Santos. As quantificações foram realizadas através das técnicas de INAA, fluorescência de raio-X e espectrometria gama. Foram identificados arsênio e cromo em concentrações superiores ao Threshold Effect Level (TEL ou nível de efeito limiar - limite de concentração onde não se espera ocorrência de efeitos biológicos adversos) em todos os perfis analisados. As concentrações de zinco apresentaram resultados superiores ao TEL nas fatias de alguns perfis. Os radionuclídeos ${ }^{238} \mathrm{U}$ e ${ }^{232} \mathrm{Th}$ apresentaram concentrações superiores a média mundial nas amostras coletadas em regiões próximas do Polo Industrial de Cubatão, o canal da Cosipa, do porto de Santos e da drenagem de municípios. As fatias superficiais dos perfis analisados apresentaram concentração média de urânio de $5,5 \mathrm{mg} \cdot \mathrm{kg}^{-1}$ e de tório de $10,5 \mathrm{mg} \cdot \mathrm{kg}^{-1}$. 
Amorim (2012) realizou o estudo em sedimentos superficiais do estuário de Santos/São Vicente e do estuário de Cananéia, onde as concentrações de metais foram determinadas através de diversas técnicas analíticas. Os resultados obtidos, para as amostras de Cananéia, para elementos traços determinados por INAA identificaram poucos pontos com concentrações de arsênio e cromo superiores ao TEL. Entretanto, o fator de enriquecimento (FE) calculado com base em dados determinados por Armelin e Saiki (2009) indica possível entrada de contaminantes de origem antrópicas. A respeito dos radionuclídeos naturais, foi determinada para o estuário de Cananéia uma concentração média de urânio de $1,5 \mathrm{mg} \cdot \mathrm{kg}^{-1}$ e de tório de $4,8 \mathrm{mg} \cdot \mathrm{kg}^{-1}$, e para o estuário de Santos/São Vicente determinou-se a concentração média de urânio de $2,5 \mathrm{mg} \cdot \mathrm{kg}^{-1}$ e de tório de $7,9 \mathrm{mg} \cdot \mathrm{kg}^{-1}$.

A TAB. 1 apresenta compilação dos resultados de quantificação de urânio e tório em sedimentos superficiais no sistema Cananéia-lguape e em áreas próximas da região em diversos trabalhos.

TABELA 1 - Concentração de urânio e tório em amostras de sedimento superficial publicados em estudos nas regiões de Cananéia e Baixada Santista.

\begin{tabular}{|c|c|c|c|}
\hline Trabalho & Região & $\begin{array}{c}\text { Concentração urânio } \\
\left(\mathrm{mg} \cdot \mathrm{kg}^{-1}\right)\end{array}$ & $\begin{array}{c}\text { Concentração tório } \\
\left(\mathrm{mg} \cdot \mathrm{kg}^{-1}\right)\end{array}$ \\
\hline Amorim, 2012 & Cananéia & 0,3 a 4,8 & 0,8 a 30,5 \\
\hline Amorim, 2012 & $\begin{array}{l}\text { Baixada } \\
\text { Santista }\end{array}$ & 0,5 a 7,1 & 1,2 a 19,1 \\
\hline $\begin{array}{l}\text { Armelin e Saiki, } \\
2009\end{array}$ & Cananéia & 2,7 & 14,6 \\
\hline Damatto, 2010 & $\begin{array}{l}\text { Baixada } \\
\text { Santista }\end{array}$ & 1,2 a 12 & 4,4 a 15 \\
\hline $\begin{array}{c}\text { Ferreira et al., } \\
1986\end{array}$ & Cananéia & 0,6 a 2,9 & 0,8 a 12 \\
\hline
\end{tabular}

Ainda há que se considerar que a produção mineradora ainda continua com atividades na região do Vale do Ribeira. Atualmente, os principais produtos extraídos na região são materiais para a indústria da construção civil, como areia, brita, cascalho, argila e calcário, a rocha fosfática e a produção de fertilizantes fosfatados (IPT, 2007 e 2008). Do ponto de vista da radioproteção, 
a extração de rocha fosfática e a produção de fertilizantes fosfatados são atividades que devem ser monitoradas, pois, a rocha fosfática pode conter em sua composição quantidades consideráveis de urânio e tório, enquanto que o processo de produção de fertilizantes fosfatados tem como subproduto o fosfogesso, material reconhecido por reter grandes quantidades de tório (Saueia et al., 2005). Na região do Vale do Ribeira estão localizadas as maiores minas de extração de rocha fosfatada do estado de São Paulo (DNPM, 2016a e 2016b). Na cidade de Registro, que extraiu 65.201 t de fosfato em 2014 (DNPM, 2016b), encontra-se a Socal S/A, uma extratora de rocha fosfática de porte médio (IPT, 2007 e 2008). Na cidade de Cajati, que extraiu 5.446.850 t de fosfato em 2014 (DNPM, 2016b), fica a Vale Fertilizantes, que realiza a extração de rocha fosfática e também produz fertilizante fosfatado.

Portanto surgiu a ideia deste trabalho de determinar os níveis de concentração de urânio e tório nos sedimentos superficiais do sistema Cananéia-Iguape, para estabelecer os valores basais da região, que podem ser utilizados como referência para futuros estudos, e verificar possível contaminação por NORM neste sistema.

\subsection{Técnicas analíticas para determinação de urânio e tório}

Existem várias técnicas analíticas que podem ser aplicadas para a quantificação de urânio e tório nos mais diversos tipos de amostras ambientais. Entre elas pode-se destacar a análise por ativação neutrônica instrumental (INAA), a espectrometria alfa, a espectrometria de massa com fonte de plasma induzido (ICP-MS) e a espectrofotometria. Tratam de técnicas versáteis que atingem resultados com exatidão e precisão adequada para a quantificação de amostras ambientais.

A INAA tem como base a reação do tipo $(n, \gamma)$, onde um nêutron atinge o núcleo de átomo estável com uma colisão inelástica, formando um núcleo composto altamente excitado. O núcleo neste estado precisa eliminar a energia excedente para atingir um estado estável, por isto ele passa por processos de desintegração, processo o qual envolve emissões de partículas ou raios gama prontos. Na maioria dos casos esse processo leva a formação de um núcleo 
radioativo que decairá através da emissão de raios gamas (Knoll, 2000). O método analítico consiste em medir os raios gama emitidos, pois estes são característicos para cada isótopo, o que permite a identificação do elemento que o produziu; e sua intensidade, que é proporcional a concentração do elemento. Esta técnica possibilita a análise de até 40 elementos químicos, quantificando concentrações de até $10 \mu \mathrm{g} \cdot \mathrm{kg}^{-1}$, dependendo do elemento a ser analisado, em uma única amostra sem a necessidade de realizar nenhum tratamento químico, evitando perdas durante as reações químicas e processos aplicados (IAEA, 2001). Está característica torna esta técnica ideal para a análise de amostras sólidas, dispensando processos químicos para sua abertura. No entanto ela depende de uma fonte de alto fluxo de nêutrons, geralmente encontrado em reatores nucleares de pesquisa. Além disso, durante algum tempo as amostras tornam-se uma fonte radioativa, necessitando cuidados especiais para sua manipulação. Há também que se considerar o tempo de meia vida do nuclídeo formado, isto porque nuclídeos com tempo de meia vida muito curto podem decair antes de sua contagem no detector gama.

O ICP-MS trata-se de um equipamento formado por uma fonte de plasma induzido (do inglês, inductively coupled plasma) acoplado a um espectrômetro de massa (do inglês, mass spectrometer). A amostra, em estado líquido, é injetada na forma de aerossol na fonte de plasma induzido, onde ela sofre ionização pelo plasma de argônio. O feixe iônico formado é lançado ao espectrômetro de massa, que separa cada íon em função da razão massa/carga, e em seguida é detectado em um detector de elétrons. Trata-se de uma técnica de análise multielementar extremamente sensível, capaz de quantificar isótopos na faixa $\mathrm{ng} \cdot \mathrm{kg}^{-1}$, rápida e que necessita poucos microlitros de amostra (Holler, 2009). Entretanto o custo para adquirir este equipamento é muito alto, e amostras com altos teores de sólidos não podem ser analisadas, devido ao risco de danificar o ICP-MS.

A espectrometria alfa se baseia na interação entre a partícula alfa, uma partícula de carga 2+ formada por dois prótons de dois nêutrons, com um meio detector. Durante essa interação é possível, através de um sistema eletrônico, identificar a energia de cada partícula alfa que interage com o detector, 
possibilitando a identificação do nuclídeo emissor. A partir do espectro formado quantifica-se o nuclídeo pela relação entre a intensidade com sua concentração (Knoll, 2000). Este tipo de análise é altamente sensível a interferências externas, pois as partículas alfa interagem com qualquer material. Para torná-la efetiva é necessário que o detector trabalhe sob vácuo, impedindo a interação entre o ar e a partícula alfa, e a amostra deve ser depositada na forma de uma fina camada sobre uma placa metálica, pois se esta camada for muito espessa pode absorver a partícula alfa que ela mesma emite, num fenômeno conhecido como auto absorção. Também para garantir melhores resultados é importante remover radioisótopos que emitam partículas alfa de energias próximas, para evitar sobreposição no espectro formado. Contudo, permite quantificar isótopos na faixa de concentração de $\mu \mathrm{g} \cdot \mathrm{kg}^{-1}$, e através do espectro formado pela interação entre as partículas alfa de diferentes cargas energéticas é possível determinar a razão isotópica de elementos.

A espectrofotometria é uma técnica que utiliza como princípio básico a variação da intensidade da cor de uma substância em função da concentração de um de seus componentes. O espectrofotômetro é formado pela junção de dois equipamentos: o espectrômetro e o fotômetro. O espectrômetro é responsável por dispersar a radiação eletromagnética, permitindo restringir o comprimento de onda na faixa espectral desejada. $O$ fotômetro realiza a medida da intensidade de radiação transmitida. Com isto é possível observar a variação da intensidade de radiação eletromagnética num comprimento de onda desejado ao interagir com soluções com concentrações diferentes do analito. Levando em consideração a lei de Beer-Lambert, que estabelece uma relação entre a concentração de uma substância e a intensidade de luz que a atravessa, é possível realizar quantificações de elementos químicos (Vogel, 1981). Como esta técnica utiliza equipamentos simples, como espectrofotômetro, ela é uma alternativa de baixo custo, embora apresente limite de detecção menor que os demais métodos, na faixa do $\mathrm{mg} \cdot \mathrm{kg}^{-1}$.

Como este trabalho se propõe a quantificar urânio e tório em amostra de sedimentos superficiais, optou-se em aplicar a técnica de espectrofotometria. Isto se deve ao fato de o Laboratório de Radiometria Ambiental (LRA) do Instituto de Pesquisas Energéticas e Nucleares (IPEN) já aplicar os métodos de 
INAA e espectrometria alfa para quantificação de amostras de sedimento. Entretanto, o laboratório necessita um método alternativo mais rápido, pois os métodos, da forma que são executados, demandam, no mínimo, 7 dias, enquanto o método espectrofotométrico proposto, demanda 4 dias. 


\section{Objetivo}

O objetivo principal do presente trabalho é de quantificar as concentrações de urânio e tório em amostras de sedimento superficial do sistema Cananéia-Iguape, para estabelecer uma baseline, que possa ser usada como referência para futuros estudos, e verificar possível contaminação por NORM neste sistema.

O objetivo secundário deste estudo é disponibilizar uma técnica alternativa aos métodos de análise através de INAA e espectrometria alfa aplicados no LRA do IPEN. A determinação de urânio e tório por INAA é dependente do funcionamento do reator de pesquisas IRA-R1 do IPEN e deve atender os procedimentos de radioproteção estabelecidos pelo IPEN. Com isto este procedimento demora três semanas para ser realizado por completo. Já a determinação por espectrometria alfa necessita que a amostra seja dissolvida, e a etapa de medida no espectrômetro alfa demora dois dias. No total, a determinação por espectrometria alfa demanda uma semana para ser realizada por completo. Este estudo propõe a aplicação do método baseado na extração com solvente, seguida da espectrofotometria com Arsenazo III. Este procedimento necessita que a amostra de sedimento seja dissolvida, para então ser submetida à etapa de extração com solventes e análise espectrofotométrica. No total este procedimento demanda três dias para ser realizado. Este método já foi aplicado em diversos estudos de quantificação de urânio e tório em diversas matrizes (Fukuma et. al, 2000; Fukuma et. al, 2001; Silva et. al, 2001; Siqueira et. al, 2007). 


\section{Metodologia}

\subsection{Coleta de amostras de sedimento do sistema Cananéia-Iguape}

As amostras de sedimentos do sistema Cananéia-Iguape foram coletadas pelo IOUSP em março de 2011. Foram analisadas 28 amostras de sedimento superficial coletados com um amostrador do tipo Van Veen, sendo estas frações pertencentes as mesmas amostras analisadas por Tramonte (2014). Estas amostras foram submetidas a um processo de liofilização, para então serem maceradas e guardadas em recipientes de plástico. Na FIG. 7 está representada a localização das amostras coletadas, e na TAB.TABELA 2 as coordenadas geográficas (Tramonte, 2014). 
TABELA 2 - Coordenadas das amostras de sedimento superficial coletadas no sistema Cananéia-Iguape

\begin{tabular}{c|c|c}
\hline Amostra & Longitude (으) & Latitude (-9) \\
\hline P01 & $47^{\circ} 34,068^{\prime}$ & $24^{\circ} 40,900^{\prime}$ \\
\hline P02 & $47^{\circ} 34,019^{\prime}$ & $24^{\circ} 41,074^{\prime}$ \\
\hline P03 & $47^{\circ} 34,291^{\prime}$ & $24^{\circ} 41,526^{\prime}$ \\
\hline P04 & $47^{\circ} 34,312^{\prime}$ & $24^{\circ} 41,804^{\prime}$ \\
\hline P05 & $47^{\circ} 34,235^{\prime}$ & $24^{\circ} 41,985^{\prime}$ \\
\hline P06 & $47^{\circ} 34,138^{\prime}$ & $24^{\circ} 42,229^{\prime}$ \\
\hline P12 & $47^{\circ} 32,630^{\prime}$ & $24^{\circ} 42,395^{\prime}$ \\
\hline P13 & $47^{\circ} 32,318^{\prime}$ & $24^{\circ} 42,263^{\prime}$ \\
\hline P14 & $47^{\circ} 31,766^{\prime}$ & $24^{\circ} 41,797^{\prime}$ \\
\hline P17 & $47^{\circ} 30,559^{\prime}$ & $24^{\circ} 41,992^{\prime}$ \\
\hline P18 & $47^{\circ} 28,479^{\prime}$ & $24^{\circ} 41,960^{\prime}$ \\
\hline P19 & $47^{\circ} 27,893^{\prime}$ & $24^{\circ} 41,843^{\prime}$ \\
\hline P23 & $47^{\circ} 33,018^{\prime}$ & $24^{\circ} 42,547^{\prime}$ \\
\hline P24 & $47^{\circ} 33,146^{\prime}$ & $24^{\circ} 42,747^{\prime}$ \\
\hline P28 & $47^{\circ} 34,368^{\prime}$ & $24^{\circ} 43,631^{\prime}$ \\
\hline P29 & $47^{\circ} 34,815^{\prime}$ & $24^{\circ} 43,980^{\prime}$ \\
\hline P35 & $47^{\circ} 35,285^{\prime}$ & $24^{\circ} 44,430^{\prime}$ \\
\hline P36 & $47^{\circ} 35,499^{\prime}$ & $24^{\circ} 44,430^{\prime}$ \\
\hline P39 & $47^{\circ} 37,778^{\prime}$ & $24^{\circ} 45,620^{\prime}$ \\
\hline P42 & $47^{\circ} 39,831^{\prime}$ & $24^{\circ} 47,141^{\prime}$ \\
\hline P43 & $47^{\circ} 40,382^{\prime}$ & $24^{\circ} 47,689^{\prime}$ \\
\hline P44 & $47^{\circ} 40,921^{\prime}$ & $24^{\circ} 48,335^{\prime}$ \\
\hline P52 & $47^{\circ} 48,533^{\prime}$ & $24^{\circ} 54,105^{\prime}$ \\
\hline P53 & $47^{\circ} 50,392^{\prime}$ & $24^{\circ} 54,196^{\prime}$ \\
\hline P54 & $47^{\circ} 50,912^{\prime}$ & $24^{\circ} 55,512^{\prime}$ \\
\hline P60 & $47^{\circ} 53,973^{\prime}$ & $24^{\circ} 59,195^{\prime}$ \\
\hline P63 & $47^{\circ} 55,297^{\prime}$ & $25^{\circ} 01,138^{\prime}$ \\
\hline & $47^{\circ} 55,018^{\prime}$ & $25^{\circ} 01,919^{\prime}$ \\
\hline & &
\end{tabular}




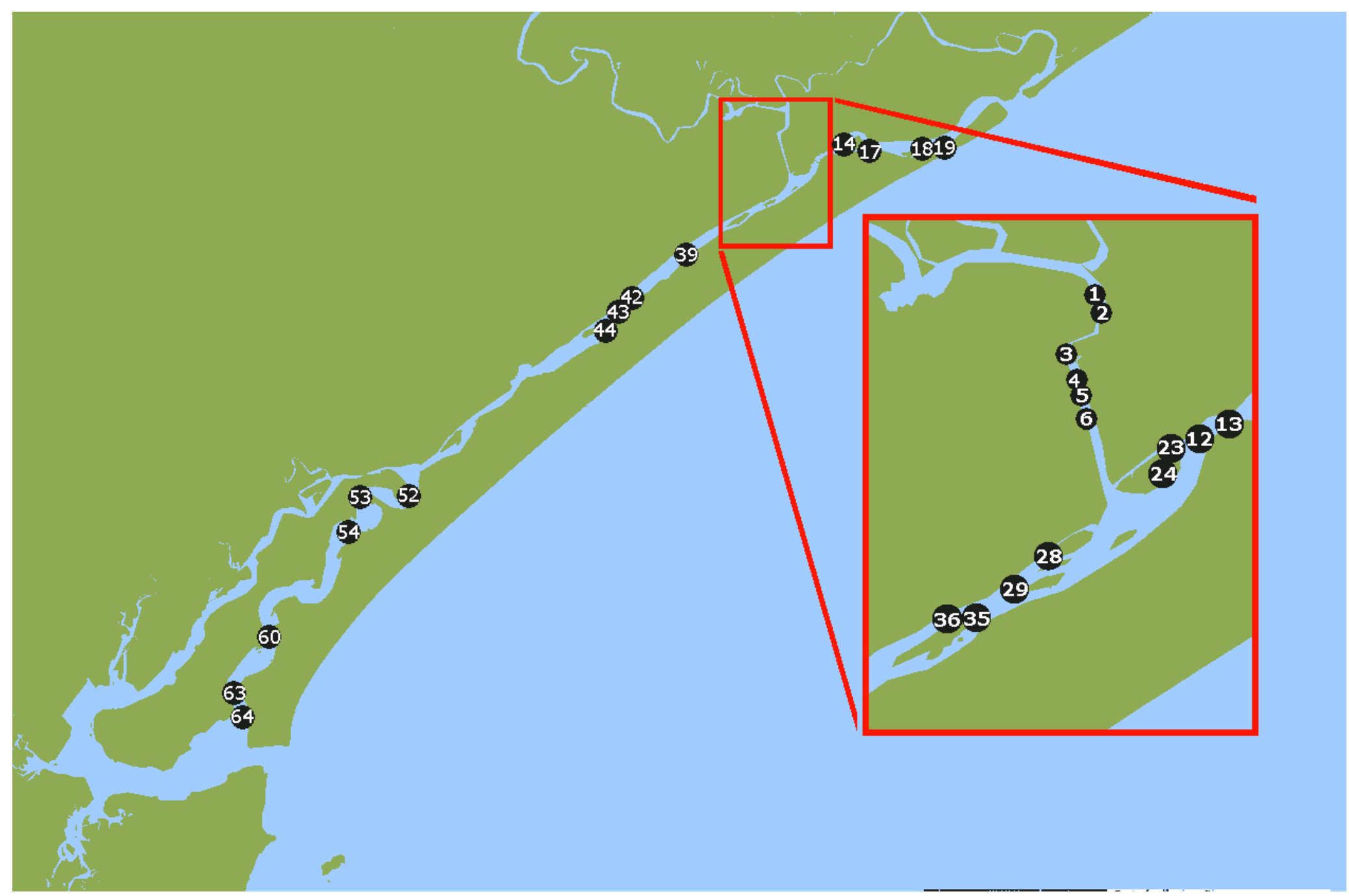

FIGURA 7 - Localização das amostras de sedimento superficial coletadas no sistema Cananéia-Iguape. 


\subsection{Digestão ácida das amostras}

Os materiais de referência certificados (MRC) IAEA-SL-1 e IAEA-SL-3 da Agência Internacional de Energia Atômica (IAEA) e as amostras de sedimento precisaram ser dissolvidos para que fossem analisados. Para garantir uma dissolução completa do urânio e tório presentes e obter uma eliminação mais efetiva da matéria orgânica, realizou-se uma digestão ácida num micro-ondas CEM Mars 5, empregando uma adaptação do método de digestão acida de matrizes complexas da "United States Environmental Protection Agency" (EPA, 1996).

Uma massa de $0,5000 \mathrm{~g}$ da amostra foi pesada no tubo de politetrafluoretileno (PTFE) do digestor e adicionaram-se $6 \mathrm{~mL}$ de $\mathrm{HNO}_{3}$ concentrado, $0,5 \mathrm{~mL}$ de $\mathrm{HF} 40 \%$ e $4 \mathrm{~mL}$ de água destilada. Após o primeiro ciclo de digestão no micro-ondas, adicionou-se ao tubo $1 \mathrm{~mL}$ de $\mathrm{H}_{2} \mathrm{O}_{2} 40 \% \mathrm{e}$ $2 \mathrm{~mL}$ de $\mathrm{HNO}_{3}$ concentrado, e iniciou-se um novo ciclo de digestão, esta etapa foi repetida mais uma vez. A solução foi então transferida para um béquer de PTFE e aquecida até atingir quase a secura total. Adicionou-se $\mathrm{HNO}_{3}$ concentrado e $\mathrm{H}_{2} \mathrm{O}_{2}$ para ressuspender a solução, e então a solução foi novamente aquecida até quase secura total, para garantir total eliminação do $\mathrm{HF}$, repetindo esta etapa mais duas vezes. Por fim, foi adicionado à solução 5 $\mathrm{mL}$ de $\mathrm{HNO}_{3}$ concentrado e água destilada até atingir o volume de $20 \mathrm{~mL}$.

O ciclo de digestão, no micro-ondas CEM Mars 5, consistiu numa rampa de aquecimento até $175^{\circ} \mathrm{C}$ durante 15 minutos, e então a temperatura foi mantida a $175^{\circ} \mathrm{C}$ por 10 minutos.

\subsection{Determinação de urânio por espectrofotometria}

A determinação do urânio baseia-se na sua extração utilizando tri-n-butilfosfato (TBP), em meio de $\mathrm{Al}\left(\mathrm{NO}_{3}\right)_{3}$, que previne interferência do fosfato e fluoreto, EDTA, que é responsável por complexar alguns íons metálicos e retira-los antes da extração do urânio, e do ácido tartárico, que mascara o zircônio presente. $O$ tório é removido pelo fluoreto na etapa da reextração. $O$ complexo formado pela reação entre o urânio e o Arsenazo(III) apresenta a cor 
vermelho-violeta, sendo o comprimento de onda de $650 \mathrm{~nm}$ o ideal para a medida da absorção.

Os reagentes utilizados neste procedimento foram preparados conforme a descrição na TAB. 3.

TABELA 3 - Preparo dos reagentes utilizados na determinação de urânio por espectrofotometria.

\begin{tabular}{|c|c|c|}
\hline Reagente & Composição & Preparo \\
\hline Complexante A & $\begin{array}{c}\text { Solução: } \mathrm{Al}\left(\mathrm{NO}_{3}\right)_{3} 900 \mathrm{~g} / \mathrm{L} \\
\text { Solução: Ácido tartárico } 20 \% \\
\text { Solução: EDTA 8,4\% }\end{array}$ & $\begin{array}{c}\text { Misturar: } \\
\bullet 1,1 \mathrm{~L} \text { de } \mathrm{Al}\left(\mathrm{NO}_{3}\right)_{3} \\
\bullet 0,2 \mathrm{~L} \text { de ácido tartárico } \\
\bullet 0,2 \mathrm{~L} \text { de EDTA }\end{array}$ \\
\hline Complexante B & $\begin{array}{l}\text { Sal: } 0,5 \mathrm{~g} \text { de } \mathrm{NH}_{4} \mathrm{NO}_{3} \\
\text { Sal: } 1 \mathrm{~g} \text { EDTA } \\
\text { Sal: } 1 \mathrm{~g} \text { CDTA } \\
\text { Solução: HNO3 1:1 }\end{array}$ & $\begin{array}{l}\text { - Dissolver os sais em } \\
800 \mathrm{~mL} \text { de água. } \\
\text { - Adicionar } \mathrm{HNO}_{3} \text { até } \mathrm{pH} 1 \\
\text { - Avolumar até } 1 \mathrm{~L} \text { (filtrar se } \\
\text { necessário) }\end{array}$ \\
\hline Tampão pH 3 & $\begin{array}{l}\text { Solução: Acetato de sódio } 0,5 \mathrm{M} \\
\text { Solução: Ácido acético } 0,5 \mathrm{M}\end{array}$ & $\begin{array}{c}\text { Misturar } \\
\text { - } 20 \mathrm{~mL} \text { acetato de sódio } \\
\text { •980 mL ácido acético } \\
\end{array}$ \\
\hline Arsenazo $0,3 \%$ & $\begin{array}{l}\text { Sal: } 0,3 \mathrm{~g} \text { Arsenazo III } \\
\text { Sal: } 0,4 \mathrm{~g} \mathrm{Na}_{2} \mathrm{CO}_{3}\end{array}$ & $\begin{array}{l}\text { Dissolver sais em água e } \\
\text { avolumar até } 100 \mathrm{~mL}\end{array}$ \\
\hline Arsenazo $0,006 \%$ & $\begin{array}{c}\text { Solução: Tampão pH } 3 \\
\text { Solução: NaF } 4 \mathrm{~g} / \mathrm{L} \text { em tampão pH } 3 \\
\text { Solução: Arsenazo } 0,3 \%\end{array}$ & $\begin{array}{c}\text { Misturar: } \\
\bullet 50 \mathrm{~mL} \text { de } \mathrm{NaF} \\
\bullet 10 \mathrm{~mL} \text { de Arsenazo } \\
\text { - Avolumar até } 500 \mathrm{~mL} \text { com } \\
\text { tampão } \mathrm{pH} 3\end{array}$ \\
\hline TBP 10\% & $\begin{array}{l}\text { Solução: TBP } \\
\text { Solução: Isooctano }\end{array}$ & $\begin{array}{c}\text { Misturar } 100 \mathrm{~mL} \text { de TBP } \\
\text { com Isooctano e avolumar } \\
\text { até } 1 \mathrm{~L}\end{array}$ \\
\hline
\end{tabular}

Para a análise de urânio, transferiu-se a amostra para um funil de separação. Adicionaram-se $10 \mathrm{~mL}$ de solução Complexante A e em seguida 10 $\mathrm{mL}$ de TBP $10 \%$. Agitou-se o funil por 1 minuto para então deixa-lo repousar por 20 minutos. Descartou-se a fase aquosa, e então se adicionou $10 \mathrm{~mL}$ de $\mathrm{HCl} \mathrm{1:1}$ ao funil. Agitou-se o funil por 1 minuto, e deixou-se em repouso por 10 minutos. Descartou-se a fase aquosa e então se adicionou 
$10 \mathrm{~mL}$ de solução Complexante B. Agitou-se o funil por 1 minuto e aguardou-se 10 minutos de repouso. Após o descarte da fase aquosa, adicionou-se $10 \mathrm{~mL}$ de Arsenazo 0,006\%. Agitou-se o funil e a primeira fase foi armazenada. Esta solução foi analisada num espectrofotômetro SHIMADZU UVMini-1240, medindo-se a absorbância da solução no comprimento de onda de $650 \mathrm{~nm}$ numa cubeta de quartzo com caminho óptico de $10 \mathrm{~mm}$.

\subsection{Determinação de tório por espectrofotometria}

$\mathrm{Na}$ quantificação do tório realiza-se sua extração utilizando-se tri-noctilfosfinóxido (TOPO) em meio de ciclohexano, removendo interferentes como ferro(III) e titânio(IV). Entretanto o zircônio, interferente importante, permanece na solução de extração, e sua remoção é feita com ácido oxálico e ácido ascórbico. Para evitar formação de precipitados ou complexos de tório na forma de fluoreto, sulfato e fosfatos a determinação é feita em meio fortemente ácido. O complexo de tório com Arsenazo(III) apresenta absorção máxima na faixa de $665 \mathrm{~nm}$, e sua razão molar é de 1:3.

Os reagentes utilizados neste procedimento foram preparados conforme a descrição na TAB. 4. 
TABELA 4 - Preparo dos reagentes utilizados na determinação de tório por espectrofotometria.

\begin{tabular}{|c|c|c|}
\hline Reagente & Composição & Preparo \\
\hline $\mathrm{HNO}_{3} 1 \mathrm{M}$ & $\begin{array}{l}\text { Solução: } \mathrm{HNO}_{3} 65 \% \\
\text { Sal: Uréia }\end{array}$ & $\begin{array}{c}\text { Misturar } \\
\text { - } 70 \mathrm{~mL} \mathrm{HNO}_{3} \\
\text { - } 400 \mathrm{~mL} \text { de água } \\
\text { - } 3 \mathrm{~g} \text { de uréia } \\
\text { - Avolumar até } 1 \mathrm{~L}\end{array}$ \\
\hline Arsenazo $0,3 \%$ & $\begin{array}{l}\text { Sal: } 0,3 \mathrm{~g} \mathrm{Arsenazo} \text { III } \\
\text { Sal: } 0,3 \mathrm{~g} \mathrm{Na}_{2} \mathrm{CO}_{3}\end{array}$ & $\begin{array}{c}\text { Dissolver sais em água e } \\
\text { avolumar até } 100 \mathrm{~mL}\end{array}$ \\
\hline Arsenazo $0,06 \%$ & Solução: Arsenazo 0,3\% & $\begin{array}{c}\text { Diluir } 20 \mathrm{~mL} \text { de Arsenazo } \\
0,3 \% \text { em água e avolumar até } \\
100 \mathrm{~mL}\end{array}$ \\
\hline TOPO & $\begin{array}{c}\text { Sal: TOPO } \\
\text { Solução: Ciclohexano }\end{array}$ & $\begin{array}{c}\text { Dissolver } 38,6 \mathrm{~g} \text { de TOPO em } \\
\text { ciclohexano e avolumar até } \\
1 \mathrm{~L}\end{array}$ \\
\hline
\end{tabular}

Para a determinação do tório transferiu-se a amostra para um funil de separação. Adicionaram-se $5 \mathrm{~mL}$ de ácido bórico $4 \%$ e mais $10 \mathrm{~mL}$ de TOPO e em seguida $1 \mathrm{~mL}$ de $\mathrm{HNO}_{3} 65 \%$. Agitou-se o funil por 30 segundos e esperouse as fases se separarem por 20 minutos. Descartou-se a fase aquosa, e então se adicionou $10 \mathrm{~mL}$ da solução de $\mathrm{HNO}_{3} 1 \mathrm{M}$. Agitou-se o funil por 30 segundos e deixou-se em repouso por 10 minutos. Descartou-se a fase aquosa, e em seguida adicionou-se $8 \mathrm{~mL}$ de ácido oxálico $5 \%$. Agitou-se, novamente, o funil por 30 segundos e aguardou-se 10 minutos. A fase aquosa foi transferida para um balão volumétrico de $25 \mathrm{~mL}$, e o funil de separação lavado com $10 \mathrm{~mL}$ de $\mathrm{HCl}$ concentrado, transferindo-se a fase aquosa de $\mathrm{HCl}$ do funil para o balão utilizado anteriormente. Adicionou-se $5 \mathrm{~mL}$ de ácido ascórbico $10 \%$ ao balão, e após 2 minutos $1 \mathrm{~mL}$ de Arsenazo 0,06\%. A solução do balão foi analisada num espectrofotômetro SHIMADZU UVMini-1240, medindo-se a absorbância da solução no comprimento de onda de $665 \mathrm{~nm}$ numa cubeta de quartzo com caminho óptico de $10 \mathrm{~mm}$. 


\subsection{Verificação do método}

Ao se implantar um método na rotina de um laboratório é importante avaliar seu desempenho e verificar se ele é capaz de atingir um nível de exigência esperado. Para isto realiza-se uma série de experimentos com o objetivo de estabelecer parâmetros que garantam que seus resultados são confiáveis e atendem a um nível de qualidade esperado. Este processo é chamado de verificação.

Para demonstrar que os métodos aplicados para a quantificação de urânio e tório em sedimentos neste trabalho conseguem apresentar resultados confiáveis e estimar sua eficiência realizou-se uma série de experimentos com base no documento orientativo do INMETRO DOQ-CGCRE-008 de junho de 2011 (INMETRO, 2011). Este documento apresenta uma série de recomendações, baseadas em normas nacionais e internacionais, de como demonstrar que um método de ensaio químico, nas condições em que é praticado, tem capacidade de atingir os resultados com qualidade exigida.

\subsubsection{Limite de detecção e limite de quantificação}

Durante a análise de amostras que podem apresentar baixos teores de analito é importante saber se o método aplicado possui a capacidade de detectar esta baixa concentração. Isso ocorre porque os métodos só conseguem identificar a presença do analito a partir de uma concentração mínima, e caso a amostra tenha uma concentração menor que está o método responde como se não existisse analito. Essa característica é conhecida por diversos nomes, sendo uma das mais empregadas Limite de Detecção (LD). Existem várias formas de determinar o LD de um método, sendo que não existe nenhuma forma que é universalmente aceita. Uma das formas mais comuns é apresentar a concentração em que a detecção do analito começa a ser problemática. Para a determinação do LD foram feitas 7 análises com amostras em branco, e utilizou-se a equação 1 para calcular o LD(INMETRO, 2011). 


$$
L D=X+3,143 \cdot D P
$$

Onde: LD $\rightarrow$ Limite de Detecção;

$X \rightarrow$ Média das concentrações do branco das 7 análises;

$3,143 \rightarrow$ Distribuição $t$ de Student para $n=7$ num intervalo de confiança de $99 \%$ (unilateral);

$\mathrm{DP} \rightarrow$ Desvio padrão das concentrações calculadas.

Amostras que apresentam concentração um pouco maior do que o LD também podem ser complicadas de quantificar, isso porque existe uma faixa de concentração logo acima do limite de detecção que não apresenta um nível aceitável de exatidão e precisão. A concentração mínima que atende estes dois requisitos representa o Limite de Quantificação (LQ) do método. A equação 2 apresenta uma das formas mais comuns de se determinar o $L Q$, sendo necessário realizar 7 análises com amostras em branco(INMETRO, 2011).

$$
L Q=X+5 \cdot D P
$$

Onde: $L Q \rightarrow$ Limite de Quantificação;

$X \rightarrow$ Média das concentrações do branco das 7 análises;

DP $\rightarrow$ Desvio padrão das concentrações calculadas.

\subsubsection{Exatidão}

Exatidão é definida como grau de concordância entre o resultado obtido através da análise de uma amostra e o valor de referência considerado, convencionalmente, verdadeiro. Quando aplicada a uma série de resultados, a exatidão representa a combinação de componentes de erros aleatórios e sistemáticos. Sua avaliação, geralmente, pode ser realizada a partir de três processos: Análise de MRC, participação de ensaios interlaboratoriais ou teste comparativo com método validado (INMETRO, 2011).

Para comprovar que 0 método aplicado apresenta capacidade satisfatória para análise de uma determinada matriz é de grande importância realizar a análise de um MRC desta mesma matriz. O MRC apresenta valores de uma propriedade específica e sua incerteza determinada para um nível de confiança, atrelados à rastreabilidade decorrente do seu fabricante; itens 
essenciais para comprovar as capacidades do método. Os resultados obtidos de replicatas de análises do MRC são comparados com os valores do certificado, a fim de estabelecer a competência do método e do laboratório. Esta comparação pode ser feita seguindo vários processos, como o erro relativo, teste de hipótese, erro normalizado e o Índice Z. O Índice z, também conhecido como $Z$-score, foi o processo escolhido neste trabalho. A equação 3 apresenta a formula matemática do índice Z (INMETRO, 2011).

$$
Z=\frac{(M-U)}{D P U}
$$

Onde: Z $\rightarrow$ Índice Z;

$M \rightarrow$ Média das concentrações obtidas;

$\mathrm{U} \rightarrow$ Concentração da amostra certificada;

DPU $\rightarrow$ Desvio padrão do ensaio de proficiência.

A avaliação do índice Z, seguindo a ISO Guia 43 (INMETRO, 2011), segue o seguinte critério:

$$
\begin{array}{cc}
|Z| \leq 2 \rightarrow \\
2<|Z| \leq 3 \\
|Z| \geq 3 \rightarrow
\end{array} \rightarrow \quad \begin{aligned}
& \text { Resultado satisfatório } \\
& \text { Resultado questionável }
\end{aligned}
$$

\subsubsection{Precisão}

A determinação da precisão tem como objetivo avaliar a dispersão de resultados entre ensaios realizados independentemente, utilizando-se uma mesma amostra em condições definidas. A forma mais comum de representala é através da repetitividade e da reprodutibilidade, expressando-as pelo desvio-padrão. Sendo a repetitividade e a reprodutibilidade dependentes da concentração do analito, é importante determina-las em várias faixas de concentração, e quando necessário a relação entre a precisão e a concentração do analito. Para casos onde não se trabalha com uma faixa de concentração muito grande é possível determinar a precisão em função do desvio padrão relativo (DPR), pois ele é normalizado com base na concentração, dessa forma se comportando de forma constante ao longo da 
faixa de interesse. A equação 4 apresenta a formula matemática do DPR (INMETRO, 2011).

$$
D P R=\frac{D P}{M} \times 100
$$

Onde: DP $\rightarrow$ Desvio padrão das concentrações calculadas;

$M \rightarrow$ Média das concentrações obtidas

Para amostras de origem ambiental, se o DPR calculado for menor do que $10 \%$ considera-se que o método apresenta precisão satisfatória.

\section{6. Índice de geoacumulação}

O índice de geoacumulação (IGeo), proposto por Müller em 1969 (Müller apud Damatto, 2010), é uma forma de estimar contaminação em sedimentos. Este índice é calculado através de uma relação entre a concentração do sedimento avaliado e da concentração média de fundo. O resultado obtido é classificado segundo uma tabela que indica o nível de contaminação (Damatto, 2010). A equação 5 apresenta a fórmula matemática para calcular o IGeo.

$$
I G e o=\log _{2} \frac{C_{a m}}{1,5 \times C_{b g}}
$$

Onde: $\mathrm{C}_{a m} \rightarrow$ Concentração da amostra analisada;

$1,5 \rightarrow$ Fator para minimizar possíveis variações da concentração de fundo causada por diferenças litológicas; $\mathrm{C}_{\mathrm{bg}} \rightarrow$ Concentração de fundo.

Como concentração de fundo, pode-se utilizar a concentração de metais encontrados na crosta terrestre. As concentrações aplicadas neste trabalho foram determinadas por Wedepohl (1995) na crosta continental superior, sendo a concentração média de urânio de $2,5 \mathrm{mg} \cdot \mathrm{kg}^{-1} \mathrm{e}$ a de tório de $10,3 \mathrm{mg} \cdot \mathrm{kg}^{-1}$. A TAB. 5 apresenta a classificação do IGeo. 
TABELA 5 - Classificação do índice de geoaculumação.

\begin{tabular}{c|c}
\hline Classificação & Valor IGeo \\
\hline Extremamente contaminado & $>5$ \\
\hline Muito contaminado a extremamente contaminado & $4-5$ \\
\hline Muito contaminado & $3-4$ \\
\hline Moderadamente contaminado a muito contaminado & $2-3$ \\
\hline Moderadamente contaminado & $1-2$ \\
\hline Não contaminado a moderadamente contaminado & $0-1$ \\
\hline Não contaminado & $<0$ \\
\hline
\end{tabular}




\section{Resultados e discussão}

\subsection{Método de determinação de urânio}

\subsubsection{Curva de calibração}

Para a confecção da curva de calibração para análise de urânio utilizou-se uma solução diluída de urânio com concentração de $1,0110 \pm 0,0040 \mathrm{mg} \cdot \mathrm{kg}^{-1}$, preparada a partir da solução padrão de urânio da marca SPECSOL $\left(1004 \pm 4 \mathrm{mg} \cdot \mathrm{kg}^{-1}\right)$. Foram pesadas cinco alíquotas contendo urânio em concentrações dentro do intervalo desejado. Essas amostras foram analisadas seguindo o método descrito no item 3.3. Na TAB. 6 estão apresentados os resultados de absorbância obtidos para as cinco amostras, a quantidade de urânio presente e a concentração final.

TABELA 6 - Resultados das análises de cinco alíquotas diferentes da solução diluída de urânio para a confecção da curva de calibração.

\begin{tabular}{c|c|c}
\hline $\begin{array}{c}\text { Massa de urânio } \\
\text { na amostra } \\
(\boldsymbol{\mu g})\end{array}$ & $\begin{array}{c}\text { Concentração da } \\
\text { solução final } \\
\left(\mathbf{m g} \cdot \mathbf{k g}^{-1}\right)\end{array}$ & $\begin{array}{c}\text { Absorbância } \\
(\mathbf{m A b s})\end{array}$ \\
\hline 0,52 & 0,05 & 5 \\
\hline 1,12 & 0,11 & 12 \\
\hline 5,10 & 0,51 & 63 \\
\hline 10,14 & 1,01 & 151 \\
\hline 15,08 & 1,51 & 217 \\
\hline
\end{tabular}

Na FIG. 8 apresenta-se a curva de calibração (massa de urânio na alíquota analisada em função da absorbância), a função da reta ajustada aos resultados e o coeficiente de determinação $\left(R^{2}\right)$ da reta. 


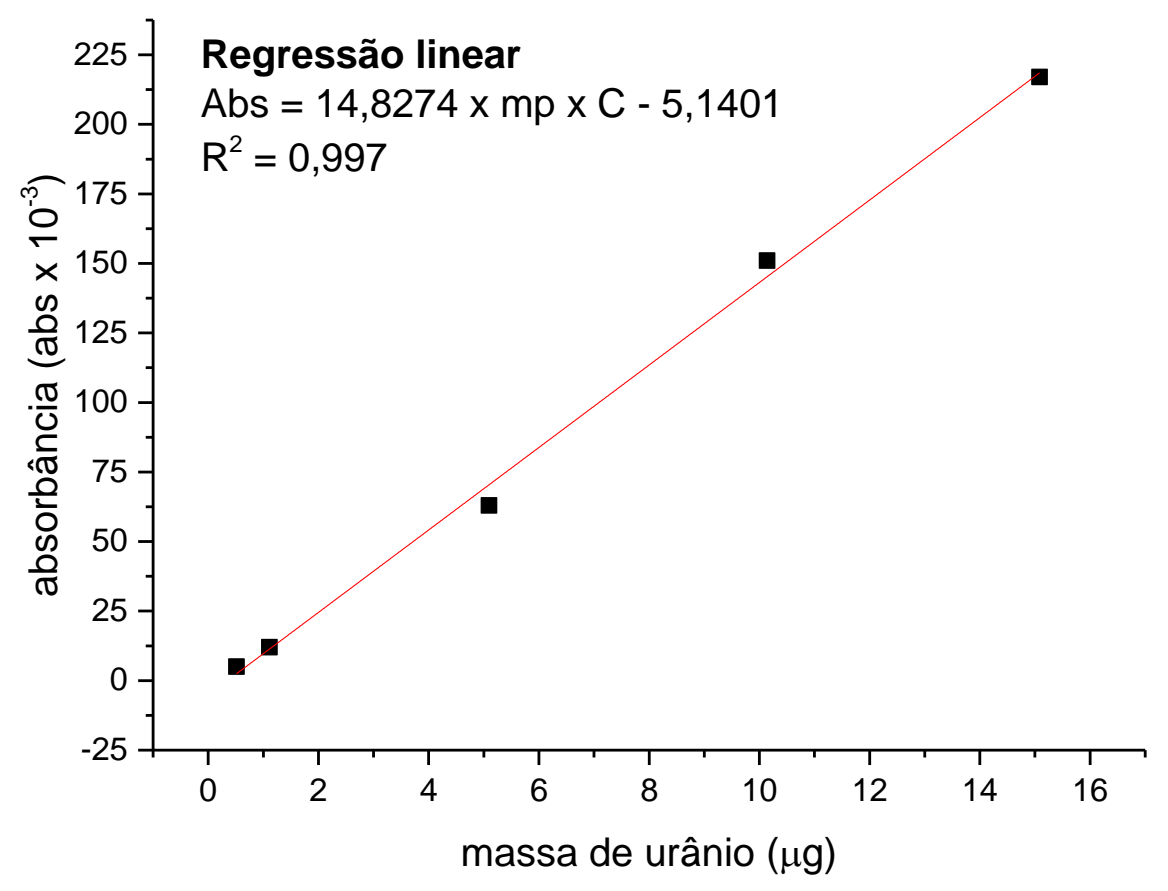

FIGURA 8 - Curva de calibração da determinação de urânio.

A equação 6 representa a equação da reta definida na curva de calibração.

$$
A B S=14,8274 \times C \times m p-5,1401
$$

Onde:ABS $\rightarrow$ Absorbância lida no espectrofotômetro (mAbs);

$\mathrm{C} \rightarrow$ Concentração de urânio da amostra $\left(\mathrm{mg} \cdot \mathrm{kg}^{-1}\right)$; $\mathrm{mp} \rightarrow$ Massa da amostra (g).

Observa-se que $\circ R^{2}$ apresenta valor superior a 0,99 , indicando que a equação obtida apresenta linearidade aceitável nesta faixa de trabalho.

\subsubsection{Verificação do método}

Para a determinação do LD e LQ do método, foram realizadas sete análises de solução "branco", solução composta de $\mathrm{HNO}_{3} 10 \%$ sem a presença de urânio, seguindo a método descrito no item 3.3. A TAB. 7 apresenta a média 
e desvio padrão das sete análises realizadas, assim como o LD e LQ calculados para método para a análise de $0,5000 \mathrm{~g}$ de amostra de sedimento superficial.

TABELA 7 - Determinação do LD e LQ da determinação de urânio.

\begin{tabular}{c|c}
\hline Analise de $\mathbf{7}$ "brancos & Concentração $\mathbf{( m g \cdot \mathbf { k g } ^ { - 1 } \mathbf { ) }}$ \\
\hline Média & 0,75 \\
\hline Desvio Padrão & 0,07 \\
\hline Limite de Detecção (LD) & 0,98 \\
\hline Limite de Quantificação (LQ) & 1,11 \\
\hline
\end{tabular}

Para verificação do método para análise de amostras de sedimentos, três análises com o MRC IAEA-SL-1 foram realizadas. As amostras foram submetidas ao procedimento de digestão ácida, descrito no item 3.2, e então à metodologia de determinação de urânio, descrita no item 3.3. Nesta verificação utilizou-se o Índice Z, para avaliar a exatidão do método, e o DPR para avaliar a precisão. Na TAB. 8 são apresentados a média das três análises realizadas com o MRC IAEA-SL-1, os valores do certificado do MRC e os resultados de exatidão e precisão.

TABELA 8 - Resultados da análise do MRC IAEA-SL-1 e cálculo da exatidão e precisão.

\begin{tabular}{c|c|c}
\hline & $\begin{array}{c}\text { Análises do MRC } \\
\left(\mathbf{m g} \cdot \mathbf{k g}^{-1}\right)\end{array}$ & $\begin{array}{c}\text { Certificado do MRC } \\
\left(\mathbf{m g} \cdot \mathbf{k g}^{-1}\right)\end{array}$ \\
\hline MÉDIA & 4,02 & 4,32 \\
\hline DESVIO PADRÃO & 0,59 & 0,08 \\
\hline \multicolumn{2}{|c}{$0 x$ atidão (Índice Z) } & \multicolumn{2}{|c}{$1,8 \%$} \\
\hline Precisão (DPR) & \multicolumn{2}{|c}{}
\end{tabular}

Como $|Z|<2$, o método apresenta exatidão satisfatória. Como o DPR $<10 \%$, o método apresenta precisão satisfatória. Portanto, os métodos 
aplicados apresentam competência para realizar análise de amostras de sedimento.

\subsection{Método de determinação de tório}

\subsubsection{Curva de calibração}

Para a confecção da curva de calibração para análise de tório utilizou-se uma solução diluída de tório com concentração de $1,0247 \pm 0,0051 \mathrm{mg} \cdot \mathrm{kg}^{-1}$, preparada a partir da solução padrão de tório da marca SPECSOL (996 $\left.\pm 5 \mathrm{mg} \cdot \mathrm{kg}^{-1}\right)$. Foram pesadas cinco alíquotas contendo tório em concentrações dentro do intervalo desejado. Essas amostras foram analisadas seguindo o método descrito no item 3.4. Na TAB. 9 estão apresentados os resultados de absorbância obtidos para as cinco amostras, a quantidade de tório presente e a concentração final.

TABELA 9 - Resultados das análises de cinco alíquotas diferentes da solução diluída de tório para a confecção da curva de calibração.

\begin{tabular}{c|c|c}
\hline $\begin{array}{c}\text { Massa de tório na } \\
\text { alíquota } \\
(\boldsymbol{\mu g})\end{array}$ & $\begin{array}{c}\text { Concentração da } \\
\text { solução final } \\
\left(\mathbf{m g} \cdot \mathbf{k g}^{-1}\right)\end{array}$ & $\begin{array}{c}\text { Absorbância } \\
(\mathbf{m A b s})\end{array}$ \\
\hline 0,51 & 0,02 & 8 \\
\hline 1,01 & 0,04 & 17 \\
\hline 5,16 & 0,21 & 82 \\
\hline 10,42 & 0,42 & 178 \\
\hline 15,38 & 0,62 & 262 \\
\hline
\end{tabular}

Na FIG. 9 apresenta-se a curva de calibração (massa de tório na alíquota analisada em função da absorbância), a função da reta ajustada aos resultados e o coeficiente de determinação $\left(R^{2}\right)$ da reta. 


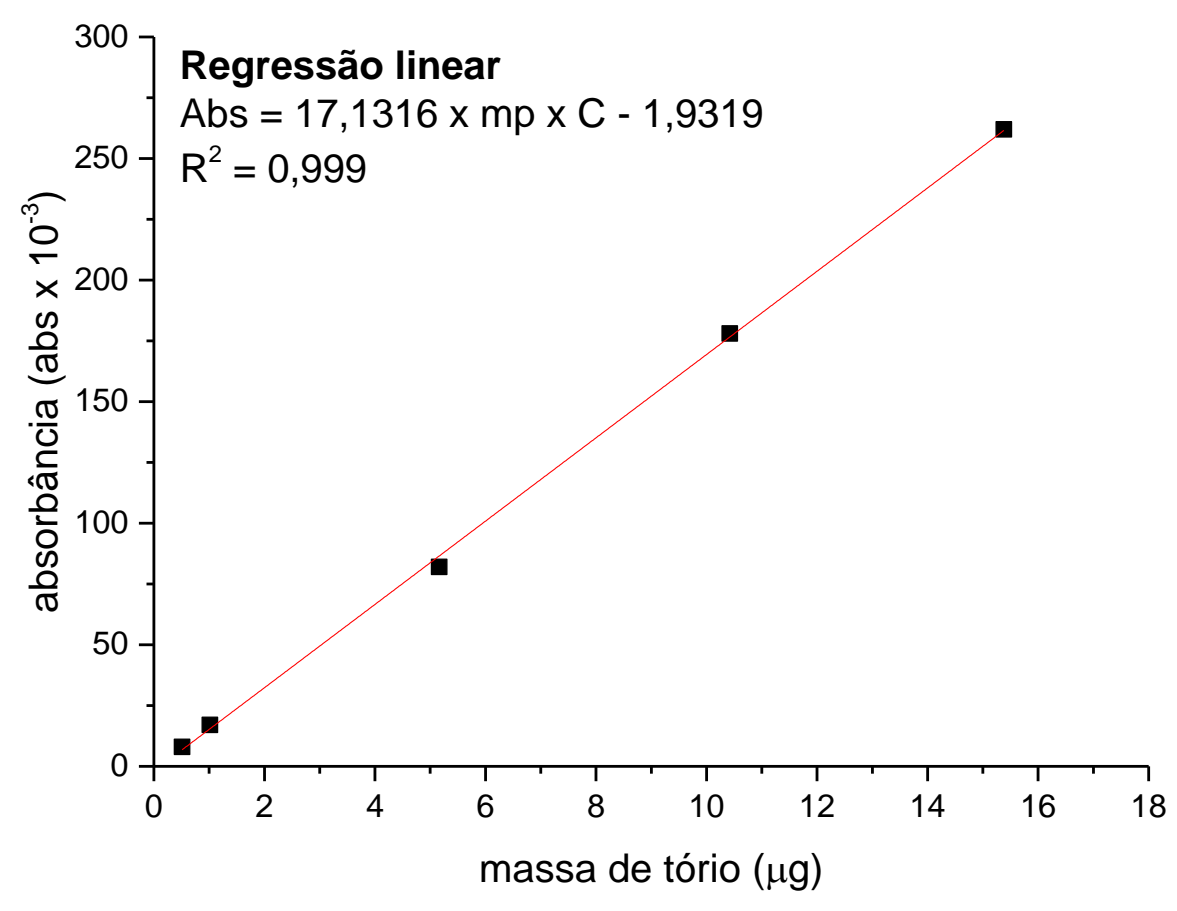

FIGURA 9 - Curva de calibração da determinação de tório.

A equação 7 representa a equação da reta definida na curva de calibração.

$$
A B S=17,1316 \times C \times m p-1,9319
$$

Onde:ABS $\rightarrow$ Absorbância lida no espectrofotômetro (mAbs);

$\mathrm{C} \rightarrow$ Concentração de tório da amostra $\left(\mathrm{mg} \cdot \mathrm{kg}^{-1}\right)$; $\mathrm{mp} \rightarrow$ Massa da amostra (g).

Observa-se que $\circ \mathrm{R}^{2}$ apresenta valor superior a 0,99 , indicando que a equação obtida apresenta linearidade aceitável nesta faixa de trabalho.

\subsubsection{Verificação do método}

Para a determinação do LD e LQ do método, foram realizadas sete análises de solução "branco", solução composta de $\mathrm{HNO}_{3} 10 \%$ sem a presença de tório, seguindo o método descrito no item 3.4. A TAB. 10 apresenta a média 
e desvio padrão das sete análises realizadas, assim como o LD e LQ calculados para método para a análise de $0,5000 \mathrm{~g}$ de amostra de sedimento superficial.

TABELA 10 - Determinação do LD e LQ da determinação de tório.

\begin{tabular}{|c|c|}
\hline Analise de 7 "brancos & Concentração $\left(\mathrm{mg} \cdot \mathrm{kg}^{-1}\right)$ \\
\hline Média & 0,26 \\
\hline Desvio Padrão & 0,11 \\
\hline Limite de Detecção (LD) & 0,61 \\
\hline Limite de Quantificação (LQ) & 0,81 \\
\hline
\end{tabular}

Para verificação do método para análise de amostras de sedimentos, três análises com o MRC IAEA-SL-3 foram realizadas. As amostras foram submetidas ao procedimento de digestão ácida, descrito no item 3.2, e então à metodologia de determinação de tório, descrita no item 3.4. Nesta verificação utilizou-se o Índice Z, para avaliar a exatidão do método, e o DPR para avaliar a precisão. Na TAB. 11 são apresentados a média das três análises realizadas com o MRC IAEA-SL-3, os valores do certificado do MRC e os resultados de exatidão e precisão.

TABELA 11 - Resultados da análise do MRC IAEA-SL-3 e cálculo da exatidão e precisão.

\begin{tabular}{c|c|c}
\hline & \multicolumn{1}{|c|}{$\begin{array}{c}\text { Análises do MRC } \\
\left(\mathbf{m g} \cdot \mathbf{k g}^{-1}\right)\end{array}$} & $\begin{array}{c}\text { Certificado do MRC } \\
\left(\mathbf{m g} \cdot \mathbf{k g}^{-1}\right)\end{array}$ \\
\hline MÉDIA & 6,31 & 7,02 \\
\hline DESVIO PADRÃO & 0,26 & 1,06 \\
\hline Exatidão (Z-Score) & \multicolumn{2}{|c}{$-0,67$} \\
\hline Precisão (DPR) & \multicolumn{2}{|c}{$4,0 \%$} \\
\hline
\end{tabular}

Como $|Z|<2$, o método apresenta exatidão satisfatória. Como 0 DPR $<10 \%$, o método apresenta precisão satisfatória. Portanto, os métodos 
aplicados apresentam competência para realizar análise de amostras de sedimento.

\subsection{Determinação da concentração de urânio e tório nos sedimentos do sistema Cananéia-Iguape}

As amostras de sedimentos do sistema Cananéia-Iguape foram analisadas seguindo os métodos descritos nos itens 3.2, 3.3 e 3.4. As concentrações e incertezas de urânio estão representadas na FIG. 10 e as concentrações de tório e incertezas estão representadas na FIG. 11.

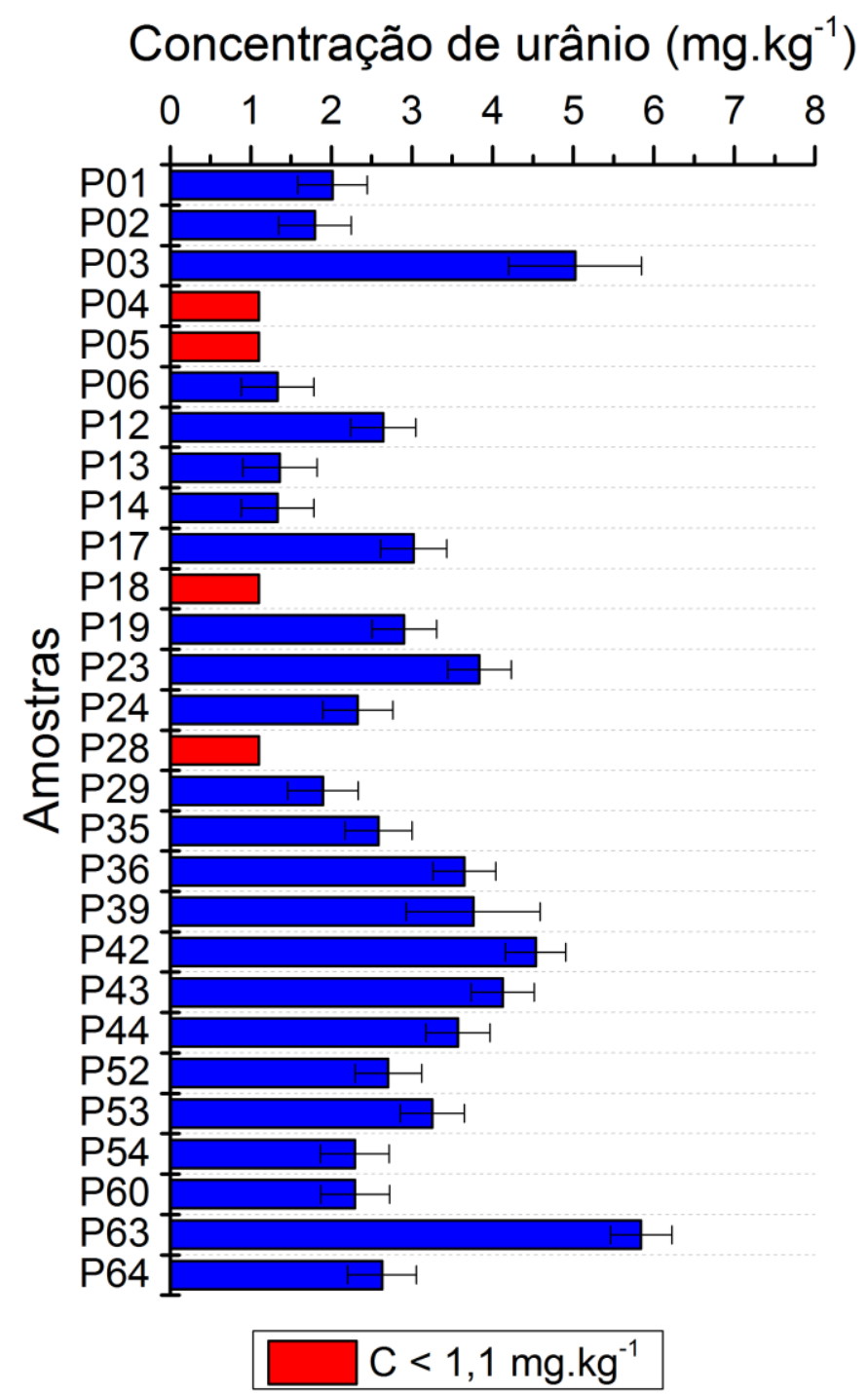

FIGURA 10 - Concentração e incerteza de urânio $\left(\mathrm{mg} \cdot \mathrm{kg}^{-1}\right)$ nas amostras de sedimento superficial do sistema Cananéia-Iguape. 


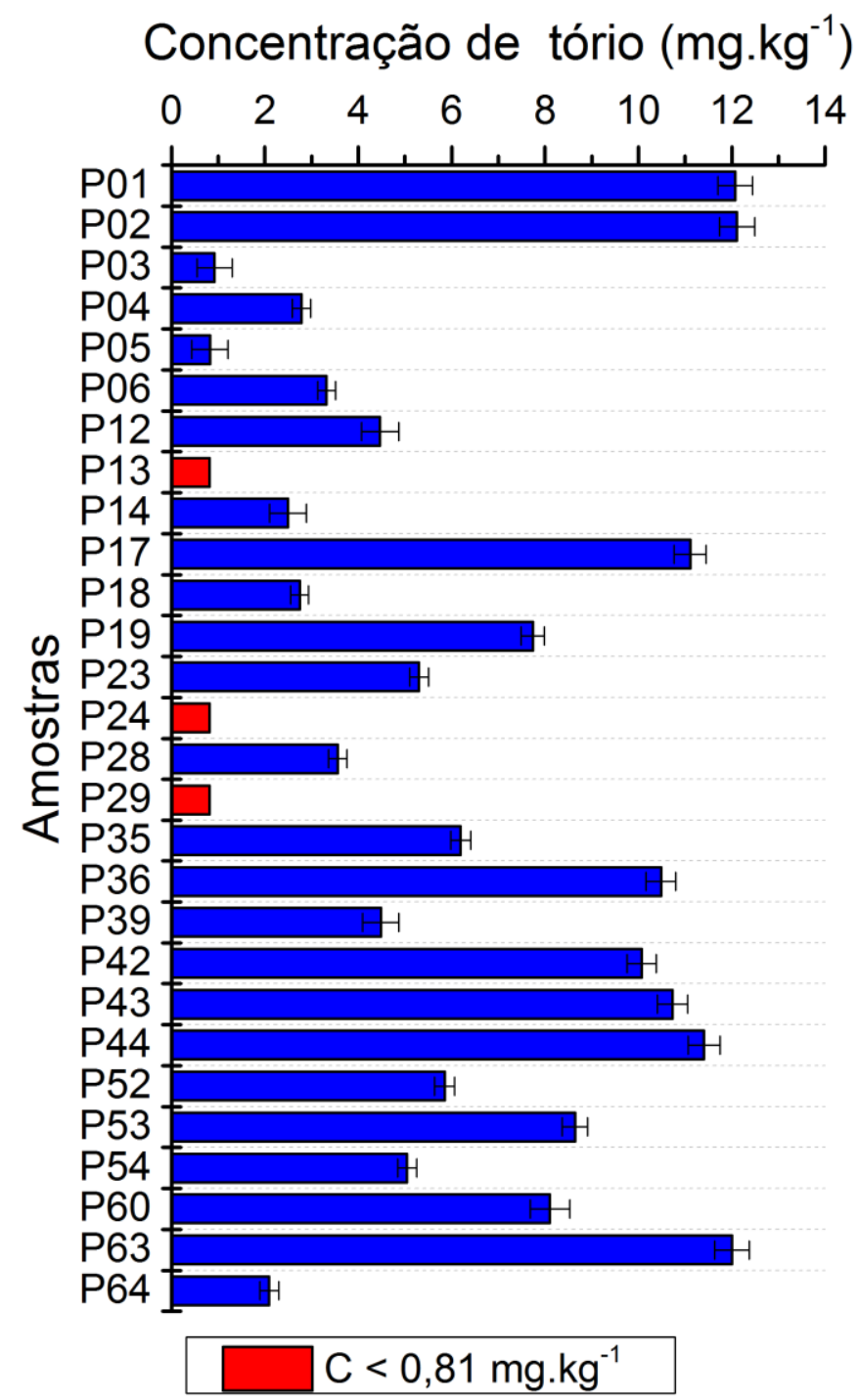

FIGURA 11 - Concentração e incerteza de tório $\left(\mathrm{mg} \cdot \mathrm{kg}^{-1}\right)$ nas amostras de sedimento superficial do sistema Cananéia-Iguape.

A FIG. 12 apresenta a distribuição da concentração de urânio no sistema Cananéia-Iguape, e a FIG. 13 apresenta a distribuição da concentração de tório. 


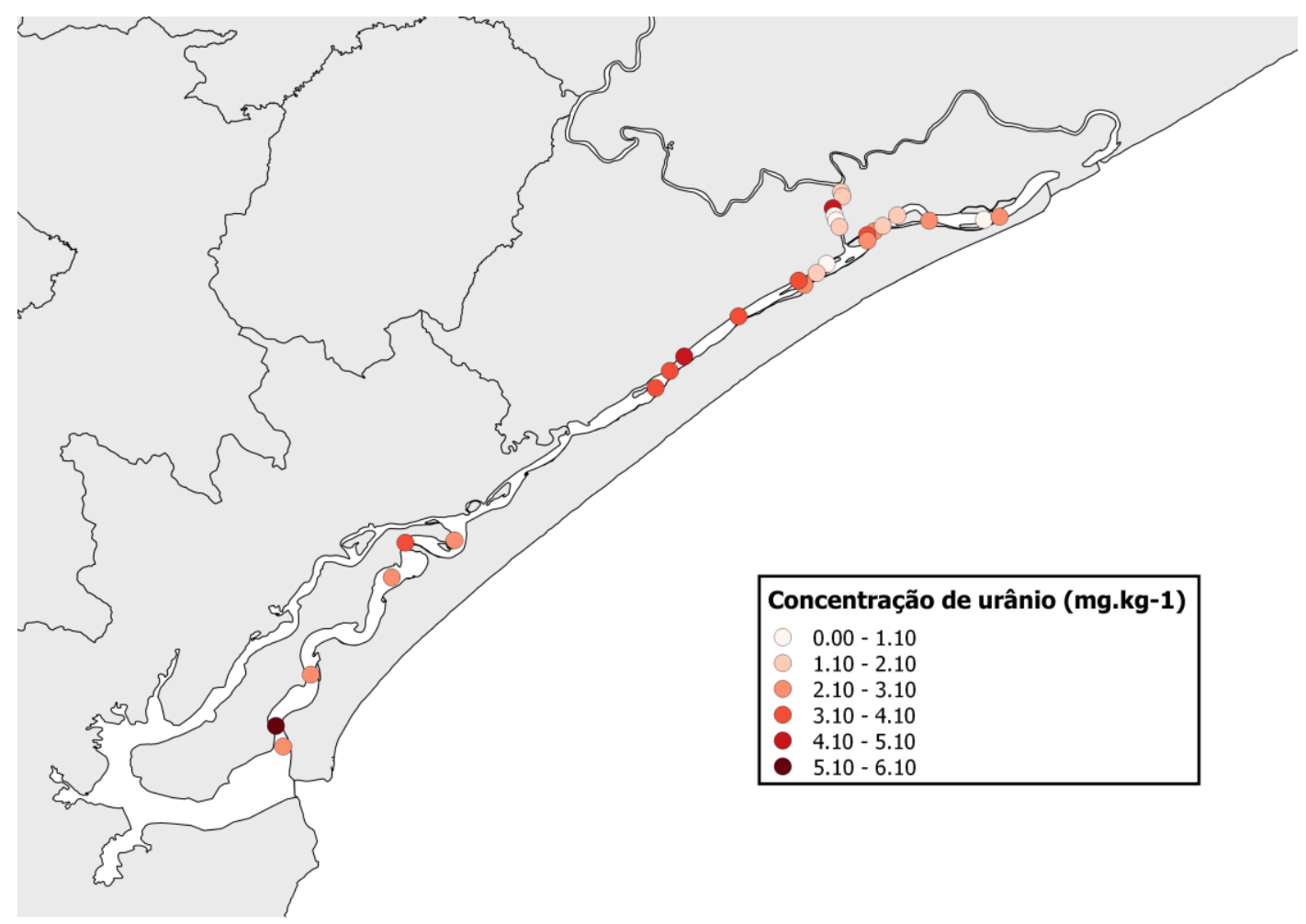

FIGURA 12 - Distribuição da concentração de urânio no sistema CananéiaIguape.

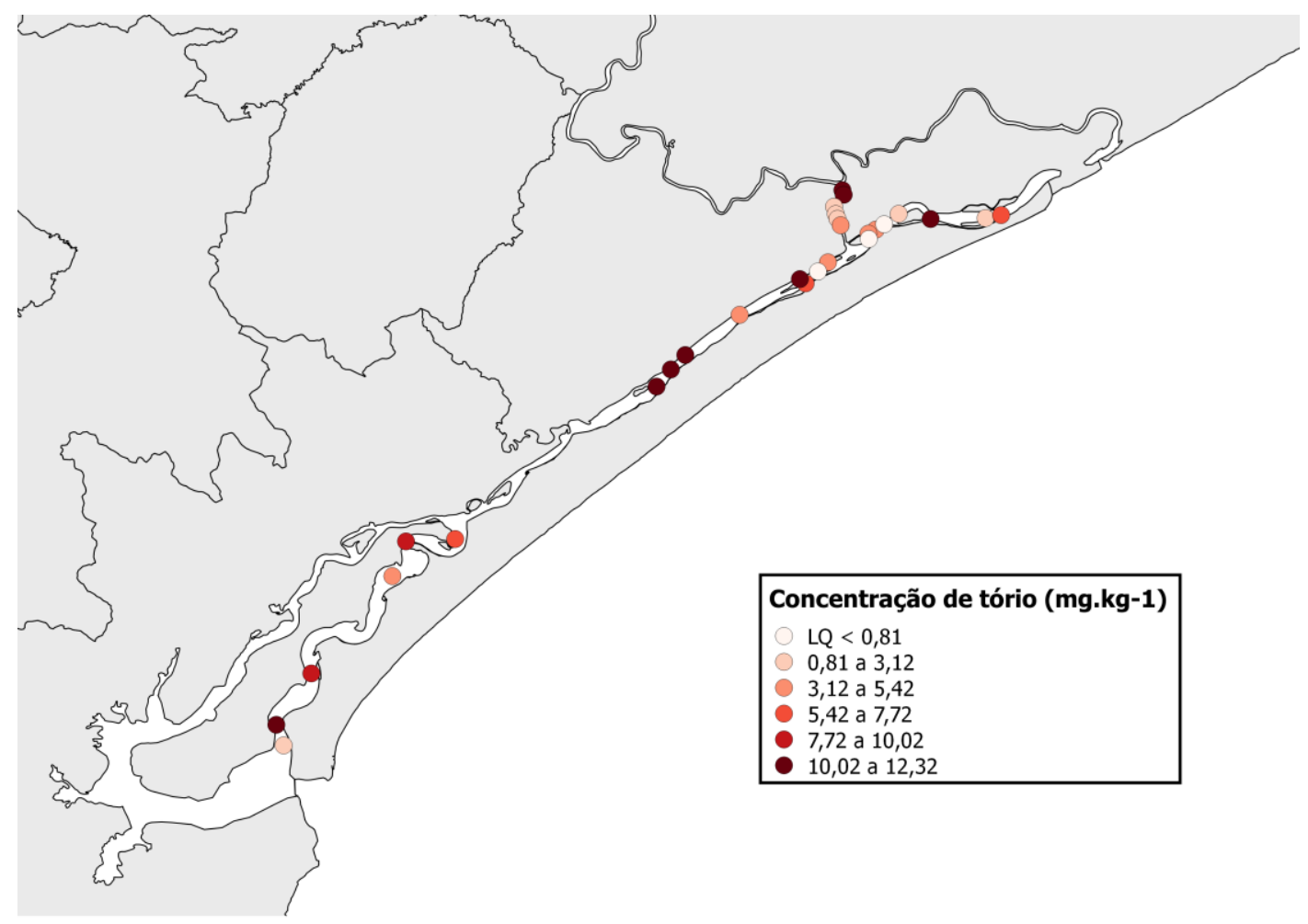

FIGURA 13 - Distribuição da concentração de tório no sistema CananéiaIguape. 
Os sedimentos superficiais apresentaram concentração média de urânio de $2,9 \mathrm{mg} \cdot \mathrm{kg}^{-1}$ (desvio padrão: $1,2 \mathrm{mg} \cdot \mathrm{kg}^{-1}$ ), e os resultados variaram de $1,3 \mathrm{mg} \cdot \mathrm{kg}^{-1}$ a $5,8 \mathrm{mg} \cdot \mathrm{kg}^{-1}$, excluindo as amostras P04, P05, P18 e P28 que apresentaram resultados abaixo do LQ do método de determinação de urânio. Já o tório apresentou concentração média $6,6 \mathrm{mg} \cdot \mathrm{kg}^{-1}$ (desvio padrão: $\left.3,8 \mathrm{mg} \cdot \mathrm{kg}^{-1}\right)$, com variação dos resultados de $0,82 \mathrm{mg} \cdot \mathrm{kg}^{-1}$ a $12,1 \mathrm{mg} \cdot \mathrm{kg}^{-1}$, excluindo as amostras P13, P24 e P29 que apresentaram resultados abaixo do LQ do método de determinação de tório. Os resultados obtidos apresentam valores próximos aos encontrados na superfície da crosta terrestre por Wedepohl (1995), onde a concentração média de urânio é de $2,5 \mathrm{mg} \cdot \mathrm{kg}^{-1} \mathrm{e}$ de tório de $10,3 \mathrm{mg} \cdot \mathrm{kg}^{-1}$.

Comparando os resultados obtidos neste estudo com a média e o intervalo da concentração de urânio e tório determinados na região de Cananéia por Amorim (2012), observa-se que os resultados são da mesma ordem de grandeza. No trabalho de Amorim (2012), a concentração média de urânio determinada foi de $1,5 \mathrm{mg} \cdot \mathrm{kg}^{-1}$, variando entre $0,3 \mathrm{mg} \cdot \mathrm{kg}^{-1}$ a $4,8 \mathrm{mg} \cdot \mathrm{kg}^{-1}$, e a concentração média de tório foi de $4,8 \mathrm{mg} \cdot \mathrm{kg}^{-1}$, variando entre $0,8 \mathrm{mg} \cdot \mathrm{kg}^{-1} \mathrm{a}$ $30,5 \mathrm{mg} \cdot \mathrm{kg}^{-1}$.

Quando os dados são comparados com o trabalho de Ferreira et al. (1986), também observa-se que os resultados obtidos neste trabalho são da mesma ordem de grandeza. É importante notar que a quantificação realizada por Ferreira et al. (1986) utilizou a técnica de espectrometria gama e considerou que as amostras de sedimento encontravam-se em equilíbrio secular. A consideração de que as amostras estariam em equilíbrio secular é passível de questionamento, pois sedimentos superficiais estão expostos a alterações químicas e físicas, devido à interação com a água, alterando o equilíbrio secular. No trabalho de Ferreira et al. (1986) a concentração média de urânio equivalente determinada foi de $1,75 \mathrm{mg} \cdot \mathrm{kg}^{-1}$, variando entre $0,6 \mathrm{mg} \cdot \mathrm{kg}^{-1}$ a $2,9 \mathrm{mg} \cdot \mathrm{kg}^{-1}$, e a concentração média de tório equivalente foi de $4,29 \mathrm{mg} \cdot \mathrm{kg}^{-1}$, variando de $0,8 \mathrm{mg} \cdot \mathrm{kg}^{-1}$ a $12 \mathrm{mg} \cdot \mathrm{kg}^{-1}$.

Da mesma forma, quando os resultados do presente estudo são comparados aos estudos de amostras de sedimentos da Baixada Santista realizados por Amorim (2012), onde as concentrações de urânio variaram de 
$0,5 \mathrm{mg} \cdot \mathrm{kg}^{-1}$ a $7,1 \mathrm{mg} \cdot \mathrm{kg}^{-1}$ e de tório entre $1,2 \mathrm{mg} \cdot \mathrm{kg}^{-1}$ a $19,1 \mathrm{mg} \cdot \mathrm{kg}^{-1}$, e com o estudo de Damatto (2010), onde as concentrações de urânio variaram de 1,2 $\mathrm{mg} \cdot \mathrm{kg}^{-1}$ a $12,0 \mathrm{mg} \cdot \mathrm{kg}^{-1}$ e de tório entre $4,4 \mathrm{mg} \cdot \mathrm{kg}^{-1}$ a $15,0 \mathrm{mg} \cdot \mathrm{kg}^{-1}$, observa-se, também, que os resultados são praticamente iguais.

Também convém comparar os resultados obtidos neste trabalho com estudo de Armelin e Saiki (2009), que determinou a concentração de urânio e tório em um perfil coletado no sul do sistema Cananéia-Iguape. Armelin e Saiki (2009) apontaram em seu trabalho que é possível observar duas faixas de concentração distintas no perfil analisado. Do topo do perfil até a camada 122-124 cm a concentração média de urânio é de $3,8 \mathrm{mg} \cdot \mathrm{kg}^{-1}$, variando entre $2,3 \mathrm{mg} \cdot \mathrm{kg}^{-1}$ a $5,3 \mathrm{mg} \cdot \mathrm{kg}^{-1}$, e a concentração de tório é de $13,2 \mathrm{mg} \cdot \mathrm{kg}^{-1}$, variando entre $8,9 \mathrm{mg} \cdot \mathrm{kg}^{-1}$ e $15,6 \mathrm{mg} \cdot \mathrm{kg}^{-1}$. A partir da camada $132-134 \mathrm{~cm}$ até o final do perfil ocorre uma queda abrupta da concentração, onde a concentração média de urânio passa a ser de $1,9 \mathrm{mg} \cdot \mathrm{kg}^{-1}$, variando entre 0,8 $\mathrm{mg} \cdot \mathrm{kg}^{-1}$ a $3,8 \mathrm{mg} \cdot \mathrm{kg}^{-1}$, e a concentração média de tório passa para $3,2 \mathrm{mg} \cdot \mathrm{kg}^{-1}$, variando de $1,8 \mathrm{mg} \cdot \mathrm{kg}^{-1}$ a $5,2 \mathrm{mg} \cdot \mathrm{kg}^{-1}$. Armelin e Saiki (2009) propuseram que esta mudança pode ter sido causada devido ao início do desague das águas do rio Ribeira de Iguape no sistema Cananéia-Iguape através do canal do Valo Grande. Comparando os resultados deste trabalho com a primeira parte do perfil analisado por Armelin e Saiki (2009) observa-se que as concentrações de urânio e de tório são da mesma ordem de grandeza.

A FIG.14 apresenta um gráfico comparando as concentrações de urânio determinadas neste trabalho com os resultados dos estudos apresentados anteriormente. Nela está representada a média das concentrações de urânio e a concentração máxima e mínima determinada em cada estudo. A FIG. 15 apresenta a mesma comparação para a concentração de tório. Como discutido anteriormente, as duas figuras mostram que os resultados obtidos no presente trabalho estão concordantes com os dados da literatura, indicando que todos apresentam concentrações com a mesma ordem de grandeza. 


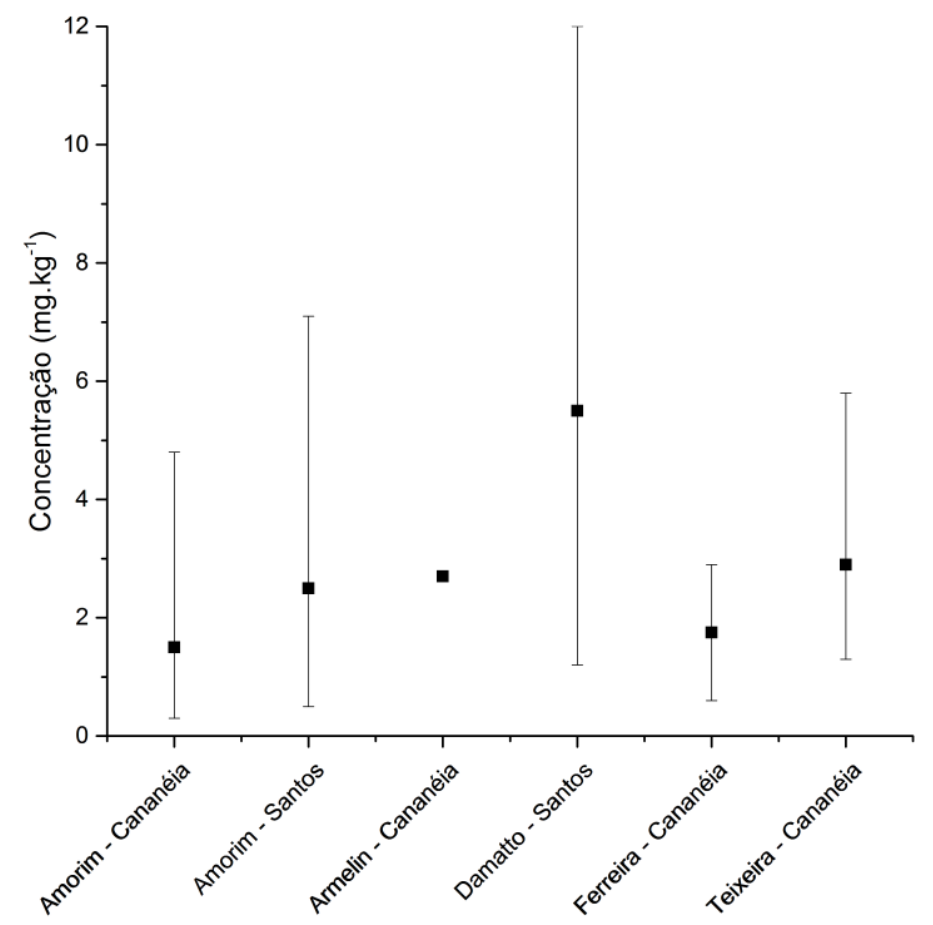

FIGURA 14 - Comparação da concentração de urânio determinada em diversos estudos de sedimentos superficiais. Representação da concentração média, máxima e mínima determinada em cada estudo.

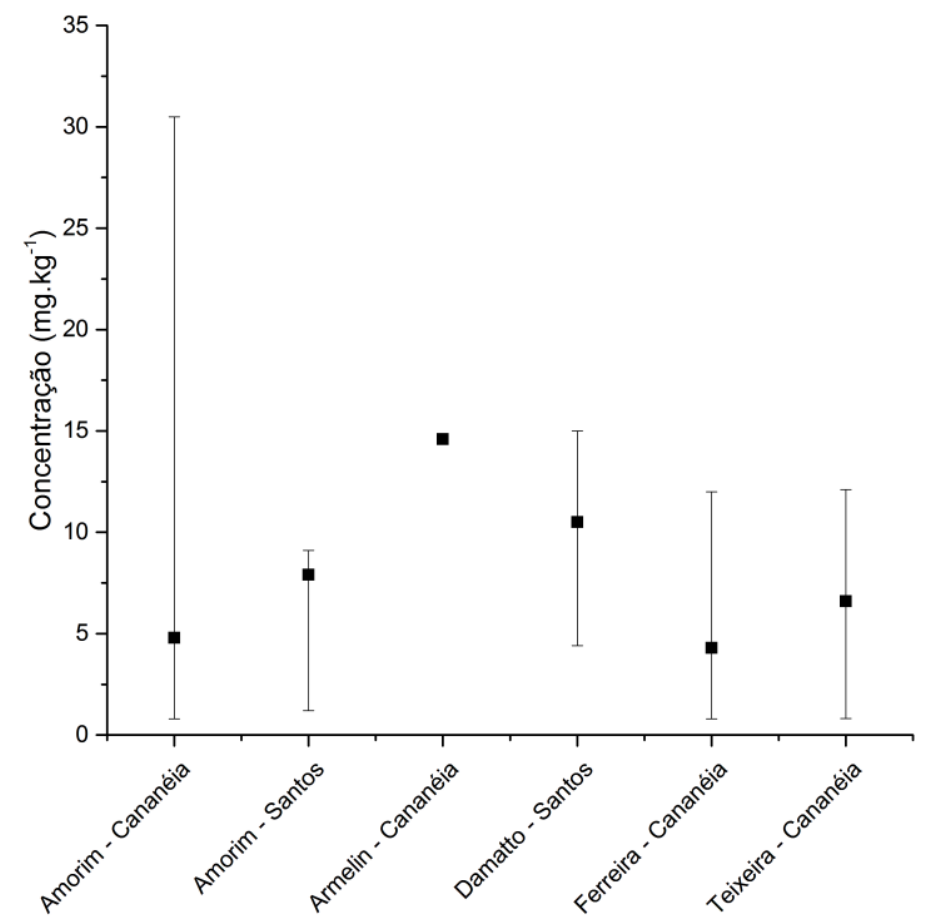

FIGURA 15 - Comparação da concentração de tório determinada em diversos estudos de sedimentos superficiais. Representação da concentração média, máxima e mínima determinada em cada estudo. 


\subsection{1. Índice de geoacumulação (IGeo)}

O IGeo foi calculado utilizando como concentração de fundo as concentrações de urânio e tório determinadas por Wedepohl (1995) para crosta continental superior. A FIG. 16 apresenta os valores de IGeo calculados de urânio, e a FIG. 17 apresenta os valores de IGeo calculado de tório.

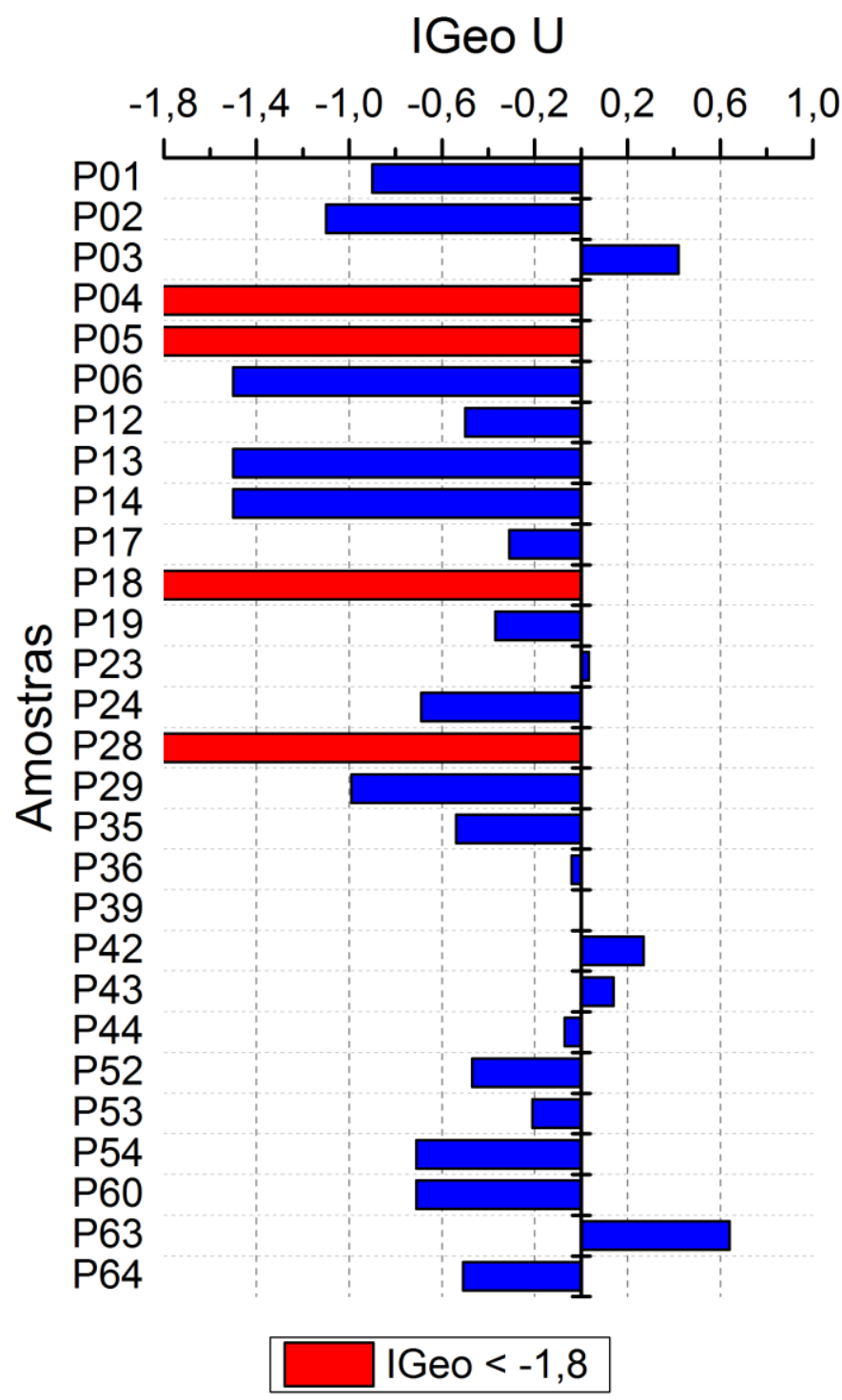

FIGURA 16 - Índice de geoacumulação (IGeo) de urânio das amostras do sistema Cananeia-Iguape 


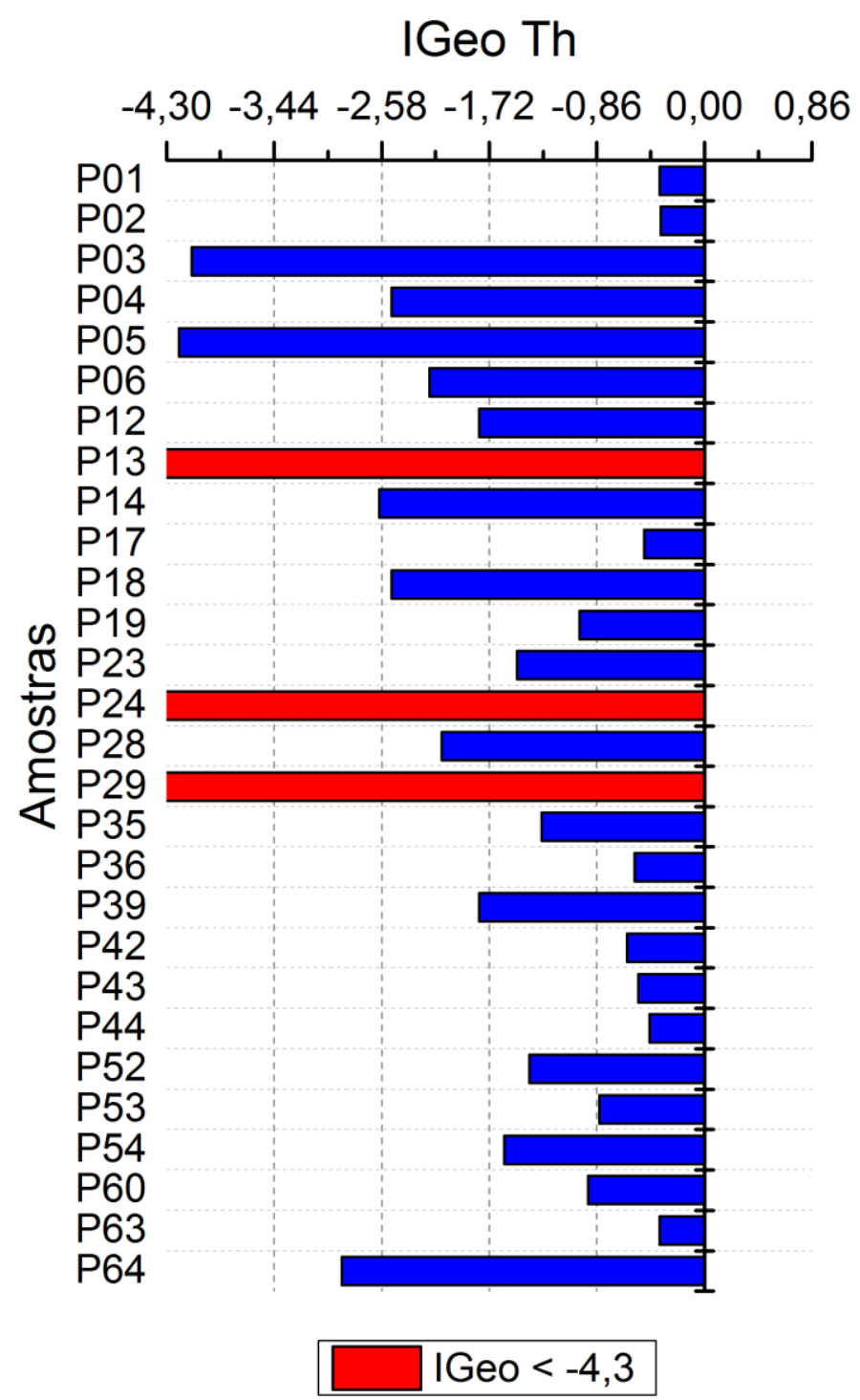

FIGURA 17 - Índice de geoacumulação (IGeo) de tório das amostras do sistema Cananeia-Iguape

Os resultados de IGeo do urânio identificaram 6 amostras, P03, P23, P42, P43, P63 e P39, com valores condizentes com a classificação "Não contaminado a moderadamente contaminado", e as outras 22 amostras possuem valores condizentes com a classificação "Não contaminado". Para os resultados de IGeo do tório, todas as amostras apresentaram valores que as classificaram como "Não contaminado". Logo é possível afirmar que os sedimentos superficiais do sistema Cananéia-Iguape analisados não sofreram contaminação por NORM. 


\subsubsection{Análise estatística}

Análises estatísticas foram realizadas com os resultados obtidos neste trabalho juntamente com os seguintes parâmetros determinados por Tramonte (2014) para as mesmas amostras de sedimento superficial: Carbono orgânico total (COT), fração de areia (\%areia), fração de silte (\%silte), fração de argila (\%argila) e concentração, em $\mathrm{mg} \cdot \mathrm{kg}^{-1}$, dos metais cobre, zinco e chumbo. Tramonte empregou duas metodologias distintas para abertura das amostras de sedimentos, o método ISO 11466, onde a amostra é submetida ao ataque ácido com água régia, e o método EPA 3050B, que realiza uma extração a quente empregando $\mathrm{HNO}_{3}, \mathrm{HCl}$ e $\mathrm{H}_{2} \mathrm{O}_{2}$. Considerando que $\mathrm{o}$ método EPA3050B é o método que mais se assemelha ao procedimento de digestão ácida aplicado neste trabalho, optou-se por utilizar os resultados, obtidos por Tramonte (2014), de concentração de cobre, chumbo e zinco determinados a partir deste método.

As análises estatísticas realizadas foram: matriz de correlação de Pearson, análise de componente principal (ACP) e análise de agrupamento. Estas análises foram feitas utilizando o software OriginPro 9.1 da OriginLab.

A matriz de correlação tem como objetivo identificar a existência da relação linear entre diversas variáveis. Nesta avaliação, calculou-se 0 coeficiente de Pearson ( $\rho$ ) para todos os parâmetros. A TAB. 12 apresenta os coeficientes de Pearson calculados para os parâmetros avaliados. 
TABELA 12 - Matriz de correlação de Pearson.

\begin{tabular}{c|c|c|c|c|c|c|c|c|c} 
& $\mathbf{U}$ & $\mathbf{T h}$ & $\mathbf{C O T}$ & \%Areia & \%Silte & \%Argila & $\mathbf{C u}$ & $\mathbf{P b}$ & $\mathbf{Z n}$ \\
\hline $\mathbf{U}$ & $\mathbf{1}$ & 0,478 & 0,178 & $-0,347$ & 0,334 & 0,353 & 0,017 & $-0,043$ & 0,104 \\
Th & 0,478 & $\mathbf{1}$ & 0,192 & $-0,433$ & 0,441 & 0,365 & 0,308 & 0,438 & 0,356 \\
COT & 0,178 & 0,192 & $\mathbf{1}$ & $-0,345$ & 0,380 & 0,193 & 0,436 & 0,212 & 0,474 \\
\%Areia & $-0,347$ & $-0,433$ & $-0,345$ & $\mathbf{1}$ & $-0,992$ & $-0,920$ & $-0,458$ & $-0,346$ & $-0,441$ \\
\%Silte & 0,334 & 0,441 & 0,380 & $-0,992$ & $\mathbf{1}$ & 0,865 & 0,472 & 0,380 & 0,466 \\
\hline \%Argila & 0,353 & 0,365 & 0,193 & $-0,920$ & 0,865 & $\mathbf{1}$ & 0,364 & 0,198 & 0,316 \\
Cu & 0,017 & 0,308 & 0,436 & $-0,458$ & 0,472 & 0,364 & $\mathbf{1}$ & 0,767 & 0,979 \\
Pb & $-0,043$ & 0,438 & 0,212 & $-0,346$ & 0,380 & 0,198 & 0,767 & $\mathbf{1}$ & 0,786 \\
Zn & 0,104 & 0,356 & 0,474 & $-0,441$ & 0,466 & 0,316 & 0,979 & 0,786 & $\mathbf{1}$
\end{tabular}

Analisando todos os $\rho$ calculados para as relações entre o urânio e os demais parâmetros, observa-se uma correlação fraca positiva $(\rho>0,3)$ com tório, fração de argila e fração de silte. Já ao analisar os $\rho$ calculados para as relações entre o tório e os demais parâmetros, identifica-se correlação fraca positiva com $\mathrm{U}, \mathrm{Cu}, \mathrm{Zn}, \mathrm{Pb}$, fração de argila e fração de silte. Tanto o urânio quanto o tório apresentaram correlação desprezível com o COT $(\rho<0,3)$. É interessante observar que os metais $\mathrm{Cu}$ e $\mathrm{Pb}$ apresentaram correlação fraca positiva com COT. A fração de areia apresentou correlação negativa com todos os metais e COT, indicando que quanto maior é a fração de areia, menor é a concentração de metais e COT.

A ACP é uma técnica de análise multivariável que busca identificar padrões em conjuntos de dados com diversas variáveis, permitindo agrupa-los de forma que seja possível observar suas similaridades e diferenças, assim tornando mais simples identificar suas inter-relações. A análise realizada utilizou a matriz de correlação de Pearson, e a TAB. 13 apresenta os coeficientes de correlação calculados de cada componente principal (CP) e sua porcentagem da variância. 
TABELA 13 - Coeficientes de correlação das componentes principais e sua porcentagem de variância.

\begin{tabular}{c|c|c|c|c}
\hline & $\mathbf{C P 1}$ & $\mathbf{C P 2}$ & $\mathbf{C P 3}$ & $\mathbf{C P 4}$ \\
\hline Urânio & 0,173 & $-\mathbf{0 , 4 0 2}$ & $\mathbf{0 , 6 1 4}$ & 0,163 \\
\hline Tório & 0,282 & $-0,117$ & 0,605 & $-0,279$ \\
\hline COT & 0,241 & 0,113 & 0,057 & $\mathbf{0 , 8 6 8}$ \\
\hline \%Areia & $\mathbf{- 0 , 4 0 6}$ & 0,298 & 0,275 & 0,043 \\
\hline \%Silte & $\mathbf{0 , 4 1 0}$ & $-0,265$ & $-0,255$ & $-0,016$ \\
\hline \%Argila & 0,354 & $-0,373$ & $-\mathbf{0 , 3 0 9}$ & $-0,124$ \\
\hline $\mathbf{C u}$ & 0,370 & 0,409 & $-0,052$ & 0,004 \\
\hline $\mathbf{P b}$ & 0,313 & $\mathbf{0 , 4 2 5}$ & 0,105 & $-\mathbf{0 , 3 4 9}$ \\
\hline $\mathbf{Z n}$ & 0,374 & 0,407 & 0,056 & 0,046 \\
\hline \% Variância & $\mathbf{5 0 , 4 7}$ & $\mathbf{2 0 , 1 7}$ & $\mathbf{1 1 , 3 0}$ & $\mathbf{9 , 5 7}$ \\
\hline
\end{tabular}

Observa-se que CP1 e CP2 são responsáveis por 70,64\% da variância total, indicando que as demais componentes não apresentam grande relevância ao estudo. A CP1 apresenta maior coeficiente de correlação positivo com a fração de silte, e coeficientes de correlação positivo com fração de argila, $\mathrm{U}$, Th, COT, Cu, Pb e Zn. Já o coeficiente de correlação com a fração de areia é o único com valor negativo. A CP2 apresenta maior coeficiente de correlação positivo com o $\mathrm{Pb}$, e coeficientes de correlação positivos com fração de areia, COT, Cu, e Zn. O menor coeficiente de correlação foi calculado com $U$, sendo que o coeficiente com fração de argila, fração de silte e Th também são negativos. As demais componentes principais calculados representam 20,87\% da variância total, indicando que não apresentam grande relevância ao estudo. Na FIG. 18 está representada a dispersão das amostras ao longo da CP1 e CP2 (também conhecido como "Biplot"), assim como os autovetores calculados para cada um dos parâmetros. Neste gráfico é possível observar o agrupamento da fração de silte, fração de argila, concentração de $\mathrm{U}$ e concentração de Th no quarto quadrante, do COT, concentração de $\mathrm{Pb}$, concentração de $\mathrm{Zn}$ e concentração de $\mathrm{Cu}$ no primeiro quadrante e da fração de areia isolada no terceiro quadrante. Ela também apresenta os "scores" calculados para as amostras de sedimento superficial em função do CP1 e CP2. 


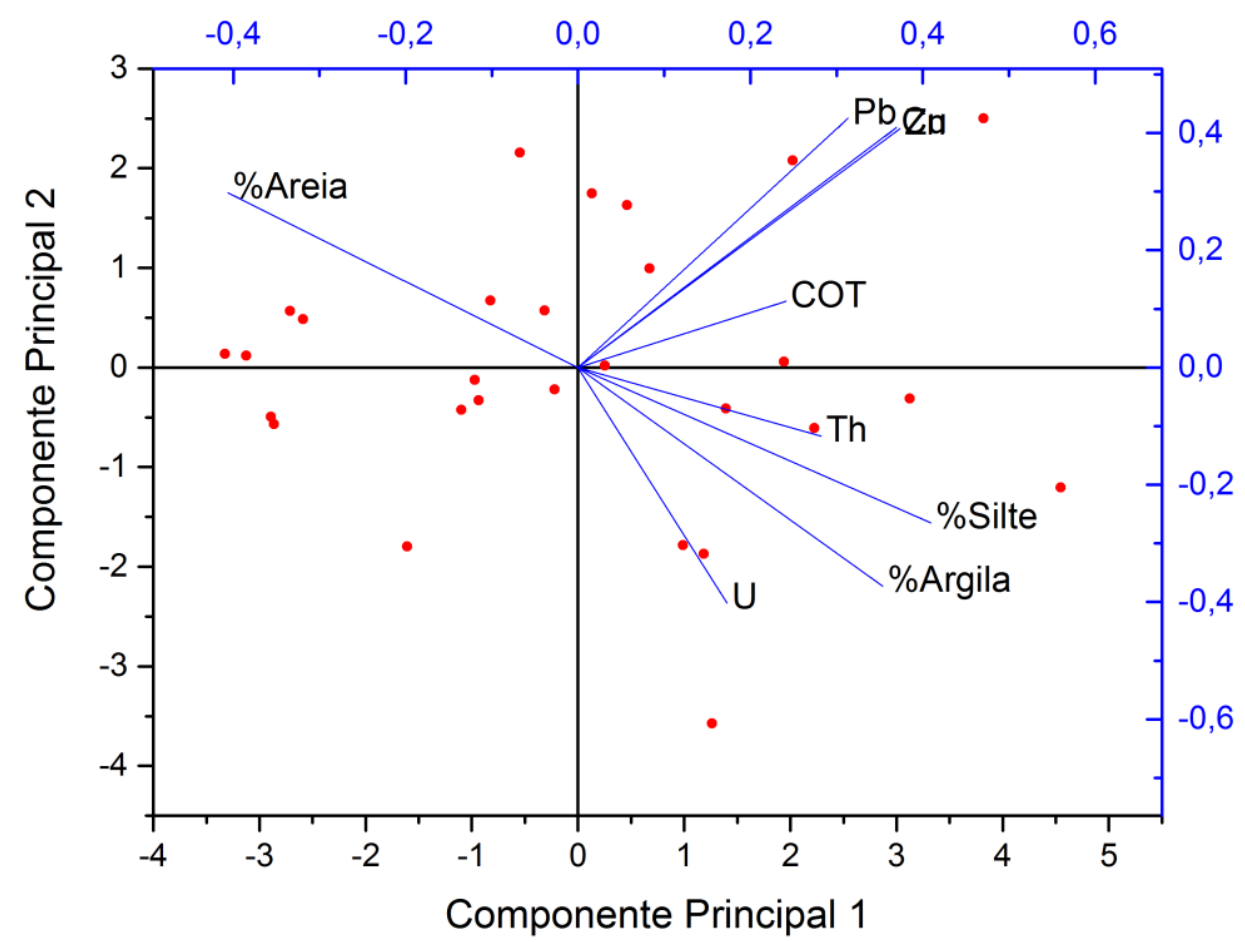

FIGURA 18 - Gráfico ACP: Dispersão dos "scores" em função do CP1 e CP2, e os autovetores calculados para cada parâmetro.

A análise de agrupamento foi realizada com o objetivo de agrupar os resultados de duas formas: agrupando a partir dos parâmetros analisados (concentração de $\mathrm{U}, \mathrm{Th}, \mathrm{Zn}, \mathrm{Pb}, \mathrm{Cu}$, fração de areia, argila e silte) com o objetivo de identificar relações entre os parâmetros, e agrupando as amostras a partir do comportamento dos parâmetros analisados com objetivo de identificar amostras com características semelhantes. Nos dois casos as análises foram feitas pela técnica de agrupamento hierárquico de Ward com a medida de similaridade através da distância Euclidiana.

A FIG. 19 apresenta o dendrograma para o agrupamento a partir dos parâmetros analisados, onde podemos observar a formação de três grupos distintos, onde no primeiro grupo estão à fração de silte, fração de argila, concentração de $U$ e concentração de Th, no segundo grupo estão a concentração de $\mathrm{Cu}$, concentração de $\mathrm{Pb}$, concentração de $\mathrm{Zn}$ e COT e em um grupo isolado a fração de areia. Este agrupamento apresentou resultado igual ao agrupamento no ACP, indicando uma concordância entre as duas técnicas 
de análise. É interessante observar que nas duas técnicas identificou-se uma maior interação entre $U$ e Th com as frações de silte e argila do que com COT, indicando uma maior importância da granulometria da amostra do que o teor COT, e que amostras com menores frações de areia apresentam maior concentração de U e de Th.

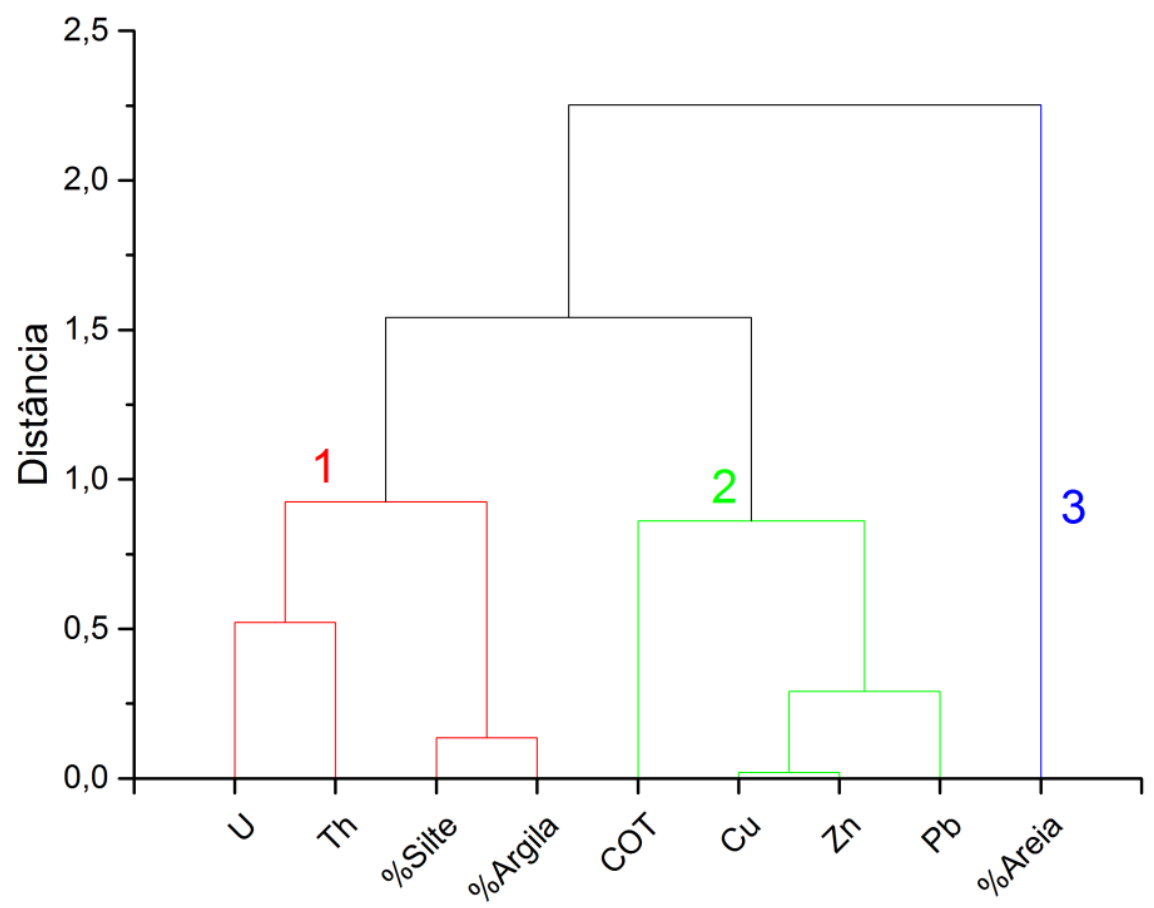

FIGURA 19 - Dendrograma agrupando os resultados obtidos para cada parâmetro em todas as amostras analisadas.

A FIG. 20 apresenta o dendrograma para o agrupamento das amostras com características semelhantes, onde é possível identificar três grupos. 


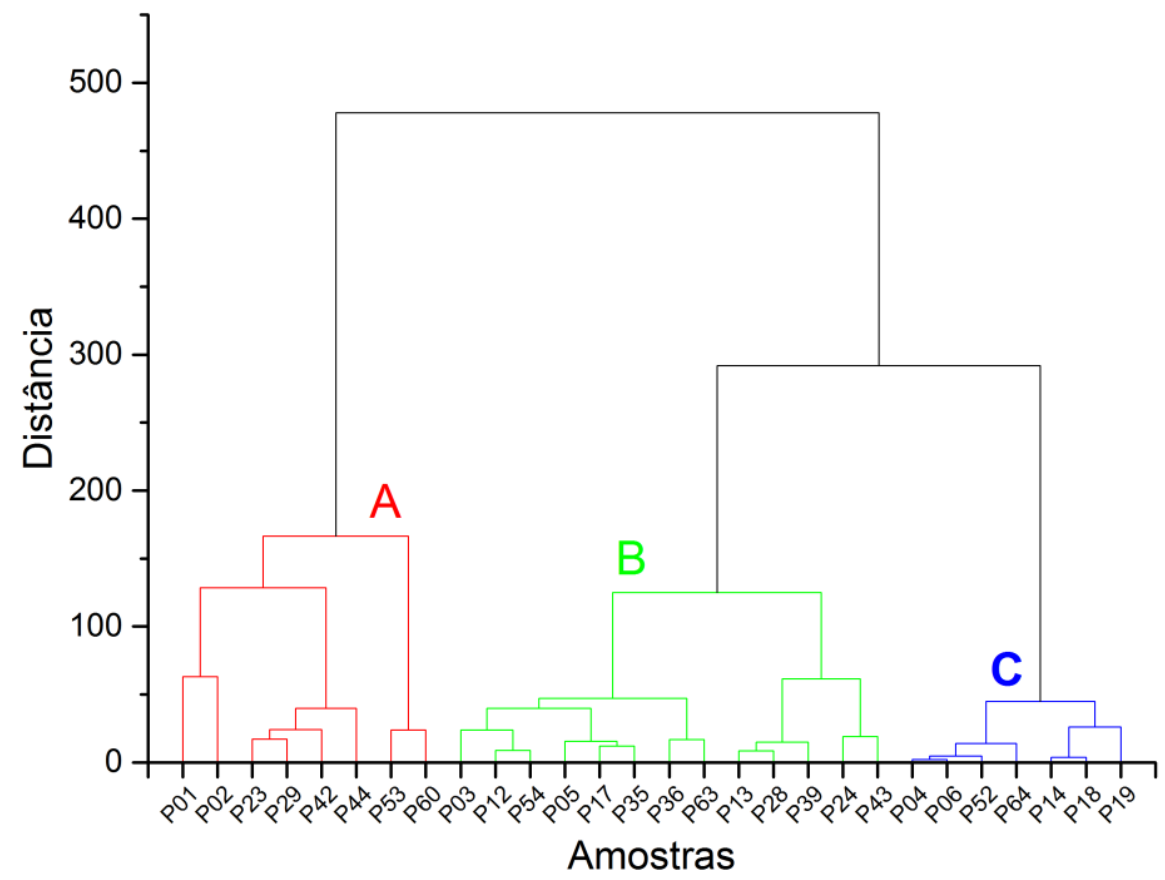

FIGURA 20 - Dendrograma agrupando as amostras em função dos parâmetros analisados

O grupo A é formado pelas amostras P01, P02, P23, P29, P42, P44, P53 e P60, e estas amostras apresentam as maiores concentrações de Th, $\mathrm{Cu}, \mathrm{Zn}$ e Pb. O grupo B é formado pelas amostras P03, P05, P12, P13, P17, P24, P28, P35, P36, P39, P43, P54 e P63, e este grupo apresenta a maior concentração de $\mathrm{U}$ e o maior COT. Já o grupo $\mathrm{C}$ é formado pelas amostras P04, P06, P14, $\mathrm{P} 18$, P19, P52 e P64, sendo que neste grupo encontram-se as amostras com maior fração de areia. A FIG. 21 apresenta a distribuição dos três grupos formados ao longo do sistema Cananéia-Iguape. 


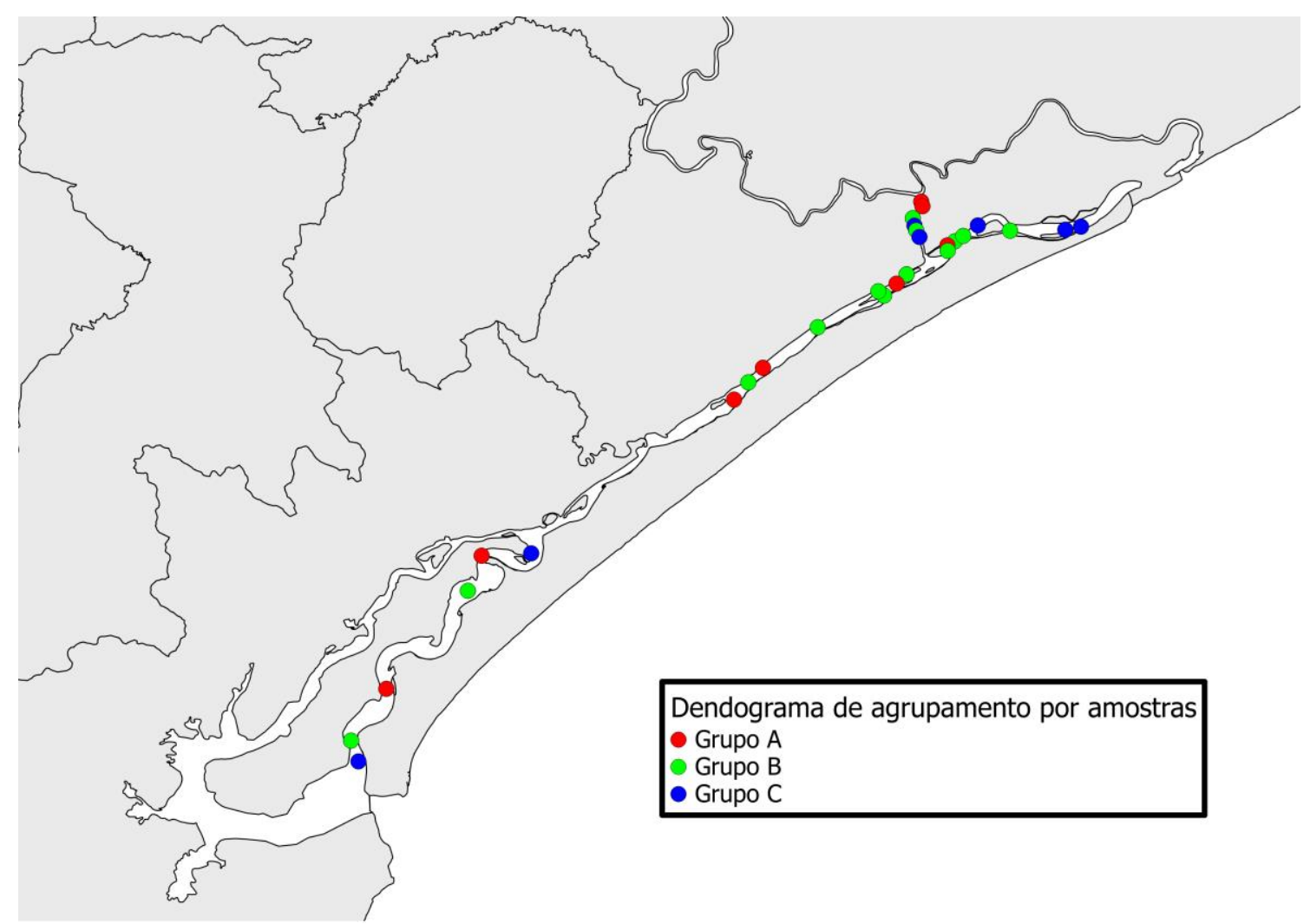

FIGURA 21 - Distribuição dos grupos, determinados pelo dendrograma de agrupamento, no sistema Cananéia-Iguape.

É possível observar que os grupos se espalham de forma heterogênea, não sendo possível identificar regiões ondem ocorram predominâncias de amostras com características bem definidas. 


\section{Conclusões}

O método espectrofotométrico para a determinação de urânio com Arsenazo III apresentou resultados satisfatórios, sendo que a curva de calibração confeccionada é adequada para ser utilizada na faixa de concnetração de $0,52 \mu \mathrm{g}$ a $15,08 \mu \mathrm{g}$ de urânio $\left(R^{2}>0,99\right)$. A verificação do método de digestão ácida de $0,5 \mathrm{~g}$ de sedimento, seguido pelo método de determinação de urânio com Arsenazo III por espectrofotometria apresentaram competência adequada. Esta competência foi comprovada pela análise do material de referência certificado IAEA-SL-1, que atingiu grau de exatidão $(|Z|<$ 2) e precisão $(D P R<10 \%)$ satisfatórios. Para a condição de análise de $0,5 \mathrm{~g}$ de sedimento foi estabelecido o limite de detecção de $0,98 \mathrm{mg} \cdot \mathrm{kg}^{-1}$ e o limite de quantificação de $1,11 \mathrm{mg} \cdot \mathrm{kg}^{-1}$.

O método espectrofotométrico para a determinação de tório com Arsenazo III apresentou resultados satisfatórios, sendo que a curva de calibração confeccionada é adequada para ser utilizada na faixa de concentração de $0,51 \mu \mathrm{g}$ a $15,38 \mu \mathrm{g}$ de tório $\left(R^{2}>0,99\right)$. A verificação do método de digestão ácida de $0,5 \mathrm{~g}$ de sedimento, seguido pelo método de determinação de tório com Arsenazo III por espectrofotometria apresentaram competência adequada. Esta competência foi comprovada pela análise do material de referência certificado IAEA-SL-3, que atingiu grau de exatidão (|Z| $<2)$

precisão

(DPR < 10\%) satisfatórios. Para a condição de análise de $0,5 \mathrm{~g}$ de sedimento foi estabelecido o limite de detecção de $0,61 \mathrm{mg} \cdot \mathrm{kg}^{-1} \mathrm{e} o$ limite de quantificação de $0,81 \mathrm{mg} \cdot \mathrm{kg}^{-1}$.

As análises dos sedimentos superficiais da região do sistema CananéiaIguape apresentaram resultados médios de $2,9 \mathrm{mg} \cdot \mathrm{kg}^{-1}$ de urânio (desvio padrão: $1,2 \mathrm{mg} \cdot \mathrm{kg}^{-1}$ ) e 6,6 $\mathrm{mg} \cdot \mathrm{kg}^{-1}$ de tório (desvio padrão: $3,8 \mathrm{mg} \cdot \mathrm{kg}^{-1}$ ). Estes resultados são concordantes com os resultados obtidos em estudos anteriores, tanto na região de Cananéia como na região da Baixada Santista. O índice de geoacumulação calculado classifica, numa avaliação conservadora, os sedimentos superficiais da região como "Não contaminado a moderadamente contaminado" para urânio e "Não contaminado" para tório. Estas informações 
indicam que os sedimentos superficiais do sistema Cananéia-Iguape, analisados neste trabalho, não estão contaminados por NORM.

As análises estatísticas realizadas identificaram afinidade entre o urânio e tório com a fração de silte e argila, indicando uma importante relação entre a granulometria das amostras com a concentração de urânio e tório. As amostras apresentam uma distribuição heterogênea quanto à concentração de urânio e tório com relação a sua localização no sistema Cananéia-Iguape, não permitindo identificar regiões com características bem definidas. 


\section{REFERÊNCIAS BIBLIOGRÁFICAS}

AMORIM, E.P. Avaliação da concentração de metais e outros elementos de interesse em amostras de sedimentos dos estuários de Santos/ São Vicente e Cananéia, estado de São Paulo, Brasil. 2012. Tese (Doutorado) - Instituto de Pesquisas Energéticas e Nucleares, São Paulo.

ARMELIN, M.J.A.; SAIKI, M. INAA applied to the multielemental characterization of a sedimentary column: a contribution to oceanographic studies. J Radioanal Nucl Chem. v. 282 p.91-94, 2009.

CEM. CEM Corporation. MARS. Operation Manual. Matthews, North California, USA 2009

CNEN. Comissão Nacional de Energia Nuclear, Diretrizes Básicas de Proteção Radiológica. CNEN-NN-3.01. Resolução no 164/14, Brasília, 2014.

CNEN. Comissão Nacional de Energia Nuclear, Requisitos de Segurança e Proteção Radiológica para Instalações Mínero-Industriais. CNEN-NN-4.01 Brasília, 2005.

DAMATTO, S.R. Radionuclídeos Naturais Das Séries Do ${ }^{238} \mathrm{U} E{ }^{232} \mathrm{Th}$, Elementos Traço e Maiores Determinados em Perfis de Sedimento da Baixada Santista para Avaliação de Áreas Impactadas. 2010. Tese (Doutorado) - Instituto de Pesquisas Energéticas e Nucleares, São Paulo.

DE VOS, W.; TARVAINEN, T. Geochemical Atlas of Europe. Part 2 Interpretation of Geochemical Maps, Additional Tables, Figures, Maps, and Related Publications. Espoo: Geological Survey of Finland, 2006 
DNPM. Departamento Nacional de Produção Mineral. Sumário Mineral 2015. Brasília, 2016a

DNPM. Departamento Nacional de Produção Mineral. Anuário Mineral Estadual - São Paulo 2015. Bras, 2016b

EPA. United States Environmental Protection Agency. Method 3052 Microwave Assisted Acid Digestion of Siliceous and Organically Based Matrices. Estados Unidos, 1996.

FUKUMA, H. T.; FERNANDES, E. A. N.; QUINELATO, A. L. Distribution of natural radionuclides during the processing of phosphate rock from ItataiaBrazil for production of phosphoric acid and uranium concentrate. Radiochimica Acta. v. 88, n. 9-11, p. 809-812, 2000

FUKUMA, H. T.; FERNANDES, E. A. N.; NASCIMENTO, M. R. L.; QUINELATO, A. L. Separation and spectrophotometric determination of thorium contained in uranium concentrate. J Radional Nucl Ch. v. 248, n. 3, p. 549553,2001

GUIMARÃES, V.; SÍGOLO, J.B., Associação de Resíduos da Metalurgia com Sedimentos em Suspensão - Rio Ribeira de Iguape. Geol. USP Sér. Cient. v. 8, n. 2, p. 1-10, 2008.

HOLLER, F.J.; SKOOG, D.A.; CROUCH, S.R. Princípios de análise instrumental. 6 ed. Porto Alegre: Bookman, 2009.

INMETRO. Instituto Nacional de Metrologia, Qualidade e Tecnologia. Orientação sobre validação de métodos analíticos. Revisão $n=4$. Rio de Janeiro. 2011 
IPT. Instituto de Pesquisas Tecnológicas, Bases Técnicas para o Ordenamento Territorial e Desenvolvimento Sustentável da Mineração no Vale do Ribeira - Municípios de Registro, Sete Barras, Juquiá, Miracatu, Jacupiranga e Iguape. Centro de Tecnologia de Obras de Infra-estrutura CT-Obras Seção de Recursos Minerais e Tecnologia Cerâmica - SRM . São Paulo. 2007

IPT. Instituto de Pesquisas Tecnológicas, Bases Técnicas e Modelo de Zoneamento Minerário para o Ordenamento Territorial e Desenvolvimento Sustentável da Mineração no Vale do Ribeira - Municípios de Cajati, Eldorado e Pariquera-Açu. Centro de Tecnologia de Obras de Infra-estrutura - CT-Obras Seção de Recursos Minerais e Tecnologia Cerâmica - SRM . São Paulo. 2008

KABATA-PENDIAS, A.; PENDIAS, $H$. Trace elements in soils and plants. 3 ed., Boca Raton: CRC Press, 2000.

KNOLL, G.F. Radiation Detection and Measurements. New York, N.Y: John Wiley and Sons Inc., 2000.

LEE , J.D. Quimica inorganica .Um novo texto conciso. 3 ed. Sao Paulo: Edgard Bluecher, 1980.

MAZZILLI, B.P.; MÁDUAR, M.F.; CAMPOS, M.P. Radioatividade no meio ambiente e avaliação de impacto radiológico ambiental. Instituto de Pesquisas Energéticas e Nucleares (IPEN). Universidade de São Paulo, 2013.

MORAES, M.P. Transporte de chumbo e metais associados no Rio Ribeira do Iguape, São Paulo, Brasil. 1997. Dissertação (Mestrado)Universidade Estadual de Campinas, Campinas. 
PEREIRA, E.B.; HAMZA, V.M.; FURTADO, V.V.; ADAMS, J.A.S. U, Th and $\mathrm{K}$ content, heat production and thermal conductivity of São Paulo, Brazil, continental shelf sediments: A reconnaissance work. Chemical Geology. v. 58, n. 2, p. 217-226, 1986.

SAITO, R.T.; FIGUEIRA, R.C.L.; TESSLER, M.G.; CUNHA, I.I.L. A model of recent sedimentation in the Cananeia-lguape estuary, Brazil. Radioactivity in the Environm. v. 8, p. 419-430, 2006.

SAITO, R.T.; FIGUEIRA, R.C.L.; TESSLER, M.G.; CUNHA, I.I.L. Geochronology of sediments in the Cananeia-Iguape estuary and in southern continental shelf of Săo Paulo State, Brazil J Radional Nucl Ch. v. 250, n. 1, p. 109-115, 2001.

SAUEIA, C.H.; MAZZILLI, B.P.; FÁVARO, D.I.T. Natural radioactivity in phosphate rock, phosphogypsum and phosphate fertilizers in Brazil. J Radional Nucl Ch. v. 264, n. 2, p. 445-448, 2005.

SHIMADZU. Shimadzu Corporation. Analytical e measuring instruments division. Shimadzu UV Visible Spectrophotometer UVmini-1240. Japan. 2008

SILVA, R.H.P da. Geoquimica e Impacto Ambiental do Arsênio no Vale do Ribeira (SP-BR). 1997. Dissertação (Mestrado)- Universidade Estadual de Campinas, Campinas.

SILVA, N. C.; FERNANDES, E. A. N.; CIPRIANI, M.; TADDEI, M. H. T. The natural radioactivity of Brazilian phosphogypsum. J Radional Nucl Ch. v. 249, n. 1, p. 251-255, 2001 
SIQUEIRA, M.C.; OLIVEIRA, K.A.P.; MOZETO, A.A.; TADDEI, M.H.; DIAS, F.F. A Comparison between spectrometry with Arsenazo III and nêutron activation for determination of $U$ and $T h$ in phosphogysum. Anais do INAC 2007. Vol CD-ROM, Santos, Brasil, 2007

TRAMONTE, K.M. Estudo da disponibilidade de metais em sedimentos do Sistema Cananéia-Iguape. 2014. Tese (Doutorado) Universidade de São Paulo, São Paulo.

TRAMONTE, K.M.; Figueira, R.C.L.; Ferreira, P.A. de L.; Ribeiro, A.P.; Batista, M.F.; Mahiquesa, M.M. de. Environmental availability of potentially toxic elements in estuarine sediments of the Cananéia-Iguape coastal system, Southeastern Brazil. Mar Pollut Bull. v. 103, n. 1-2, p.260-269, 2015.

UNSCEAR. United Nations Scientific Committee on the Effects of Atomic Radiation. Sources and effects of ionizing radiation. United Nations. New York. 2010.

VOGEL, A.I. Analise inorganica quantitativa. 4 ed. Rio de Janeiro: Guanabara Dois, 1981.

WEDEPOHL, K.H. The composition of the continental crust*. Geochimica et Cosmochimica Acta, v. 59, n. 7, p. 1217-1232, 1995. 
APÊNDICE A - Resultados das determinações de urânio.

A.1 Determinação das amostras do sistema Cananéia-Iguape.

\begin{tabular}{c|c|c|c|c}
\hline Amostra & Massa(g) & $\begin{array}{c}\text { Absorbância } \\
(\mathbf{m A b s})\end{array}$ & $\begin{array}{c}\text { Concentração } \\
\left(\mathbf{m g}_{\mathbf{k g}}^{-1} \mathbf{)}\right.\end{array}$ & IGeo \\
\hline P01 & 0,5071 & 10 & $2,0 \pm 0,4$ & $-0,90$ \\
\hline P02 & 0,4934 & 8 & $1,8 \pm 0,5$ & $-1,1$ \\
\hline P03 & 0,5119 & 33 & $5,0 \pm 0,8$ & 0,42 \\
\hline P04 & 0,5065 & 1 & LQ $(<1,11)$ & $<-1,9$ \\
\hline P05 & 0,5145 & 0 & LQ $(<1,11)$ & $<-1,9$ \\
\hline P06 & 0,5138 & 5 & $1,3 \pm 0,4$ & $-1,5$ \\
\hline P12 & 0,514 & 15 & $2,6 \pm 0,4$ & $-0,50$ \\
\hline P13 & 0,5025 & 5 & $1,4 \pm 0,5$ & $-1,5$ \\
\hline P14 & 0,5138 & 5 & $1,3 \pm 0,4$ & $-1,5$ \\
\hline P17 & 0,4944 & 17 & $3,0 \pm 0,4$ & $-0,31$ \\
\hline P18 & 0,4899 & 0 & $\mathrm{LQ}(<1,11)$ & $<-1,9$ \\
\hline P19 & 0,5143 & 17 & $2,9 \pm 0,4$ & $-0,37$ \\
\hline P23 & 0,4948 & 23 & $3,8 \pm 0,4$ & 0,033 \\
\hline P24 & 0,4969 & 12 & $2,3 \pm 0,4$ & $-0,69$ \\
\hline P28 & 0,4967 & 0 & $L Q(<1,11)$ & $<-1,9$ \\
\hline P29 & 0,5034 & 9 & $1,9 \pm 0,4$ & $-0,99$ \\
\hline P35 & 0,4995 & 14 & $2,6 \pm 0,4$ & $-0,54$ \\
\hline P36 & 0,5016 & 22 & $3,6 \pm 0,4$ & $-0,04$ \\
\hline P39 & 0,5048 & 23 & $3,8 \pm 0,8$ & 0,00 \\
\hline P42 & 0,5077 & 29 & $4,5 \pm 0,4$ & 0,27 \\
\hline P43 & 0,4927 & 25 & $4,1 \pm 0,4$ & 0,14 \\
\hline P44 & 0,4941 & 21 & $3,6 \pm 0,4$ & $-0,07$ \\
\hline P52 & 0,502 & 15 & $2,7 \pm 0,4$ & $-0,47$ \\
\hline P53 & 0,5006 & 19 & $3,3 \pm 0,4$ & $-0,21$ \\
\hline P54 & 0,505 & 12 & $2,3 \pm 0,4$ & $-0,71$ \\
\hline P60 & 0,5041 & 12 & $2,3 \pm 0,4$ & $-0,71$ \\
\hline P63 & 0,4864 & 37 & $5,8 \pm 0,4$ & 0,64 \\
\hline P64 & 0,4911 & 14 & $2,6 \pm 0,4$ & $-0,51$ \\
\hline & & & & \\
\hline
\end{tabular}


A.2 Determinação do LD e LQ do método.

\begin{tabular}{|c|c|c|}
\hline Amostra & Absorbância (mAbs) & Concentração $\left(\mathrm{mg} \cdot \mathrm{kg}^{-1}\right)$ \\
\hline 1 & 0 & 0,69 \\
\hline 2 & 0 & 0,69 \\
\hline 3 & 1 & 0,82 \\
\hline 4 & 0 & 0,69 \\
\hline 5 & 1 & 0,82 \\
\hline 6 & 0 & 0,69 \\
\hline 7 & 1 & 0,82 \\
\hline
\end{tabular}

A.3 Determinação do padrão IAEA-SL-1 para verificação do método.

\begin{tabular}{c|c|c|c}
\hline Amostra & Massa(g) & Absorbância (mAbs) & Concentração $\mathbf{~} \mathbf{m g} \cdot \mathbf{k g}^{-1}$ ) \\
\hline 1 & 0,5063 & 28 & 4,41 \\
\hline 2 & 0,4911 & 26 & 4,28 \\
\hline 3 & 0,4434 & 23 & 4,28 \\
\hline
\end{tabular}


APÊNDICE B - Resultados das determinações de tório

B.1 Análise das amostras do sistema Cananéia-Iguape

\begin{tabular}{c|c|c|c|c}
\hline Amostra & Massa(g) & $\begin{array}{c}\text { Absorbância } \\
\text { (mAbs) }\end{array}$ & $\begin{array}{c}\text { Concentrac̃ão } \\
\left(\mathbf{m g}^{\mathbf{m}} \mathbf{g}^{-1}\right)\end{array}$ & IGeo \\
\hline P01 & 0,4977 & 101 & $12,1 \pm 0,4$ & $-0,36$ \\
\hline P02 & 0,4864 & 99 & $12,1 \pm 0,4$ & $-0,35$ \\
\hline P03 & 0,5031 & 6 & $0,9 \pm 0,4$ & $-4,1$ \\
\hline P04 & 0,5018 & 22 & $2,8 \pm 0,2$ & $-2,5$ \\
\hline P05 & 0,4931 & 5 & $0,8 \pm 0,4$ & $-4,2$ \\
\hline P06 & 0,5086 & 27 & $3,3 \pm 0,2$ & $-2,2$ \\
\hline P12 & 0,4956 & 36 & $4,5 \pm 0,4$ & $-1,8$ \\
\hline P13 & 0,4047 & 4 & $\mathrm{LQ}(<0,81)$ & $<-4,3$ \\
\hline P14 & 0,4903 & 19 & $2,5 \pm 0,4$ & $-2,6$ \\
\hline P17 & 0,4935 & 92 & $11,1 \pm 0,3$ & $-0,48$ \\
\hline P18 & 0,5091 & 22 & $2,7 \pm 0,2$ & $-2,5$ \\
\hline P19 & 0,4897 & 63 & $7,7 \pm 0,3$ & $-1,0$ \\
\hline P23 & 0,4946 & 43 & $5,3 \pm 0,2$ & $-1,5$ \\
\hline P24 & 0,4941 & 2 & $L Q(<0,81)$ & $<-4,3$ \\
\hline P28 & 0,4903 & 28 & $3,6 \pm 0,2$ & $-2,1$ \\
\hline P29 & 0,4955 & 4 & $\mathrm{LQ}(<0,81)$ & $<-4,3$ \\
\hline P35 & 0,4989 & 51 & $6,2 \pm 0,2$ & $-1,3$ \\
\hline P36 & 0,4952 & 87 & $10,5 \pm 0,3$ & $-0,56$ \\
\hline P39 & 0,5068 & 37 & $4,5 \pm 0,4$ & $-1,8$ \\
\hline P42 & 0,4864 & 82 & $10,1 \pm 0,3$ & $-0,62$ \\
\hline P43 & 0,5001 & 90 & $10,7 \pm 0,3$ & $-0,53$ \\
\hline P44 & 0,5011 & 96 & $11,4 \pm 0,3$ & $-0,44$ \\
\hline P52 & 0,4982 & 48 & $5,9 \pm 0,2$ & $-1,4$ \\
\hline P53 & 0,486 & 70 & $8,6 \pm 0,3$ & $-0,84$ \\
\hline P54 & 0,4966 & 41 & $5,0 \pm 0,2$ & $-1,6$ \\
\hline P60 & 0,5037 & 68 & $8,1 \pm 0,4$ & $-0,93$ \\
\hline P63 & 0,486 & 98 & $12,0 \pm 0,4$ & $-0,36$ \\
\hline P64 & 0,5006 & 16 & $2,1 \pm 0,2$ & $-2,9$ \\
\hline & & & & \\
\hline
\end{tabular}


B.2 Análises do padrão IAEA-SL-3 para verificação do método

\begin{tabular}{c|c|c}
\hline Amostra & Absorbância (mAbs) & Concentração $\mathbf{( m g \cdot \mathbf { k g } ^ { - \mathbf { 1 } } )}$ \\
\hline 1 & 0 & 0,223 \\
\hline 2 & 0 & 0,23 \\
\hline 3 & 2 & 0,46 \\
\hline 4 & 0 & 0,23 \\
\hline 5 & 1 & 0,34 \\
\hline 6 & 0 & 0,23 \\
\hline 7 & -1 & 0,11 \\
\hline
\end{tabular}

B.3 Determinação do padrão IAEA-SL-3 para verificação do método.

\begin{tabular}{c|c|c|c}
\hline Amostra & Massa(g) & Absorbância (mAbs) & Concentração (mg. $\mathbf{~ g ~}^{-\mathbf{1}}$ ) \\
\hline 1 & 0,5120 & 55 & 6,49 \\
\hline 2 & 0,5177 & 55 & 6,42 \\
\hline 3 & 0,3971 & 39 & 6,02 \\
\hline
\end{tabular}

